\title{
Comparison of GRUAN Data Products for Meisei iMS-100 and Vaisala RS92 Radiosondes at Tateno, Japan
}

\author{
Shunsuke Hoshino ${ }^{1}$, Takuji Sugidachi ${ }^{2}$, Kensaku Shimizu ${ }^{2}$, Eriko Kobayashi ${ }^{3}$, Masatomo Fujiwara ${ }^{4}$, and \\ Masami Iwabuchi ${ }^{3}$ \\ ${ }^{1}$ Office of Numerical Prediction Modeling Fundamental Technology, Numerical Prediction Division, Information \\ Infrastructure Department, Japan Meteorological Agency, 1-2 Nagamine, Tsukuba, Ibaraki, 305-0052, Japan \\ ${ }^{2}$ Meisei Electric Co., Ltd., 2223 Naganumamachi, Isesaki, Gunma, 372-8585, Japan \\ ${ }^{3}$ Aerological Observatory, 1-2 Nagamine, Tsukuba, Ibaraki, 305-0052, Japan \\ ${ }^{4}$ Faculty of Environmental Earth Science, Hokkaido University, Kita 10 Nishi 5, Kita-ku, Sapporo, 060-0810, Japan
}

Correspondence: Shunsuke Hoshino (shoshino@met.kishou.go.jp)

\begin{abstract}
A total of 99 dual soundings with Meisei iMS-100 radiosonde and Vaisala RS92 radiosondes were carried out at Aerological Observatory of the Japan Meteorological Agency, known as Tateno $\left(36.06^{\circ} \mathrm{N}, 140.13^{\circ} \mathrm{E}, 25.2 \mathrm{~m}\right.$; WMO station number 47646), from September 2017 to January 2020. Global Climate Observing System (GCOS) Reference Upper-Air Network (GRUAN) data products (GDP) from both sets of radiosonde data for 57 flights were subsequently created using a documented processing program along with the provision of optimal estimates for measurement uncertainty. Differences in radiosonde performance were then quantified using these GDPs. For daytime observations, the iMS-100 temperature is around $0.5 \mathrm{~K}$ lower than RS92-GDP in the stratosphere with significant differences in the upper troposphere and lower stratosphere with RS92-GDP in consideration of combined uncertainties. For nighttime observations, the difference is around $-0.1 \mathrm{~K}$ and data are mostly in agreement. For relative humidity (RH), iMS-100 is around $1-2 \% \mathrm{RH}$ higher in the troposphere and $1 \% \mathrm{RH}$ smaller in the stratosphere than RS92, but both GDPs are in agreement for most of the profile. The mean pressure difference is $\leq 0.1 \mathrm{hPa}$, the wind speed difference is from $0.15 \mathrm{~m} \mathrm{~s}^{-1}$ to $0.01 \mathrm{~m} \mathrm{~s}^{-1}$, the wind direction difference $\leq 5^{\circ}$, and the root mean square of vector difference (RMSVD) for wind is $\leq 0.72 \mathrm{~m} \mathrm{~s}^{-1}$.
\end{abstract}

\section{Introduction}

The Aerological Observatory of the Japan Meteorological Agency (JMA), called as 'Tateno' (location: $36.06^{\circ} \mathrm{N}, 140.13^{\circ} \mathrm{E}$, $25.2 \mathrm{~m}$ above mean sea level), was established in 1920 and has played a leading role in the operation of all JMA radiosonde stations. The Tateno station was chosen as a candidate site for the Global Climate Observation System (GCOS) Reference Upper-Air Network (GRUAN; Seidel et al., 2009; Bodeker et al., 2016) in 2009, and was certificated as a GRUAN site in 2018. The Vaisala RS92-SGP radiosonde (referred to heare as RS92; Dirksen et al., 2014) was used for routine observation at Tateno site from December 2009. While RS92-SGP provides the data with high time resolution, that is, high altitude resolution, and highly reliable data, the lighter radiosonde was required to ensure safety in landfall into populated area. In response of this request, the Meisei RS-11G radiosonde (Kizu et al., 2018; Kobayashi et al., 2019; Hoshino et al., 2021), whose weight is 85 g, 
was released in 2012, and started to be used at Tateno in July 2013. Following the release of the Meisei iMS-100 radiosonde (Kizu et al., 2018; Hoshino et al., 2021), smaller $\left(55 \times 53 \times 131 \mathrm{~mm}^{3}\right)$ and lighter $(40 \mathrm{~g})$ model, in 2014, it has been used since September 2017. The temperature and humidity sensor of iMS-100 are basically identical with RS-11G, but relative humidity sensor of iMS-100 has a dedicated thermometer and GPS module is different between the two. RS-11G has also been used in operation at Syowa station (Antarctica) since March 2018, while iMS-100 has been used at Minamitorishima and other JMA stations since 2017, as well as at stations of other meteorological service providers and numerous research institutes and universities. Syowa and Minamitorishima are currently candidate GRUAN sites.

Figure 1 gives an overview of the GRUAN data stream. Raw data output from the ground system ("dc3cb" or "mwx" files for RS92 radiosonde data and "JFMT files" for iMS-100 radiosonde data) and meta-data files are submitted to GRUAN LC for archiving, and GRUAN LC issues a data processing ticket file including the data and meta-data file names, IDs for the measurement and the product, the output file name, and other elements for processing. The data processing center (PC; Lindenberg for RS92 and Tateno for iMS-100 radiosondes), collects raw data, meta-data and ticket files from GRUAN LC and performs processing to create GDP files in NetCDF format. The output GDP file are submitted to GRUAN LC. The GDP files are distributed at National Centers for Environmental Information (NCEI; ftp://ftp.ncdc.noaa.gov/pub/data/gruan/processing/ level2/) after quality checking.

The evaluation of GDP for RS-11G (RS-11G-GDP.1; Kizu et al., 2019) using GDP for RS92 (RS92-GDP.2; Sommer et al., 2012) in dual flight discussed in Kobayashi et al. (2019); the RS-11G-GDP.1 temperature is around -0.4 K lower than RS92GDP.2 in daytime measurement in stratosphere, while nighttime measurements generally agree well. The RS-11G-GDP.1 RH was $2 \% \mathrm{RH}$ smaller than the RS92-GDP. 2 for $90 \% \mathrm{RH}-100 \% \mathrm{RH}$, and the RS-11G GDP was around $5 \% \mathrm{RH}$ larger than the RS92-GDP. 2 at values lower than $50 \% \mathrm{RH}$, so RH difference exceeds $2 \% \mathrm{RH}$ between 500 and $150 \mathrm{hPa}$ in both daytime and nighttime data. The pressure difference was $0.5 \mathrm{hPa}$ in the troposphere, and the geopotential height difference was around 10 $-20 \mathrm{~m}$ in the stratosphere.

Although the sensors of iMS-100 are almost identical with RS-11G, the data processing algorithms have some distinct updates for IMS-100-GDP, such as the correction of hysteresis effect of the RH sensor and the correction of geoid model used in GPS module.

In this paper, Sect. 2 describes the instrumentation used and GRUAN data products (including a brief description of data processing) for iMS-100 and RS92. Sect. 3 outlines dual soundings and Sect. 4 describes the comparison analysis method. The comparison results are given in Sect. 5 and Sect. 6 discusses outcomes from a dual flight of iMS-100 and a chilled-mirror hygrometer, Meisei SKYDEW (Sugidachi, 2019). Sect. 7 summarizes the findings. See Appendix A for a summary of related abbreviations. 


\section{Instrumentation}

\subsection{Sensor material and specifications}

Table 1 shows the specifications of iMS-100 and RS92. More detailed specification for each model are described in Vaisala Oyj. (2013), Dirksen et al. (2014), Meisei Electric Co., Ltd. (2020) and Hoshino et al. (2021). The ground system for iMS-100 is Meisei MGPS2, ant that for RS92 was Vaisala DigiCORA III and was replaced to Vaisala MW41 in September 2019.

\subsection{GRUAN data processing for iMS-100}

Figure 2 gives an overview of GRUAN data processing for iMS-100. The ticket file (*.gpt) contains the raw data file name (*JFMT.DAT) and meta data file name $(*$.gmd), the individual identification number for observation in the GRUAN data archive, and the file name for processed data. GMDB is the abbreviation for the "GRUAN Meta DataBase", which contains information on payload equipments (such as radiosondes, balloons, parachutes, unwinders, rigs). In pre-processing, the lag of data acquisition timing in the processor between temperature / humidity and GPS related data (time and positioning) are adjusted, relative humidity is re-calibrated with additional ground check data (at the $0 \% \mathrm{RH}$ and $100 \% \mathrm{RH}$ conditions, where available), geometric altitude is corrected with the finer geoid model (see Section 2.2.3), and initial data for ascending are extracted by identifying the start and end of ascent. Usually, the end of ascent is when the radiosonde reached its maximum altitude (thus, the start of descent or the end of radiosonde signals), but ascent data are truncated to ensure its reliability in the event of missing temperature values (i.e., gaps in observation), over a period of 180 seconds or more. Initial data are processed at each step as outlined below to produce the final data. Derived data related to humidity (such as partial water vapor pressure, frost point temperature, and precipitable water vapor) are also calculated. To support climate record quality, GDP data include their uncertainty at each measurement point. The processed data are stored in NetCDF format, and the GDP for iMS-100 radiosonde data is noted as "IMS-100-GDP". The processing algorithm is documented in Hoshino et al. (2021) for detail, so outline and difference from RS-11G-GDP.1 (Kizu et al., 2018; Kobayashi et al., 2019) is described in this paper.

\subsubsection{Temperature}

An overview of temperature calculation is given in Fig. 3. $T_{0}, U_{0}, P_{\text {surf }}$ and $H_{f i n}$ are uncorrected temperature values, uncorrected relative humidity values, surface pressure and corrected geopotential height (see Sect.2.2.3). The process for calculation of provisional pressure, heat spike filtering and calculation of amount of radiation heating is same as the process for RS-11GGDP.1 (Kizu et al., 2018; Kobayashi et al., 2019). As the thermistor is not completely spherical, there is a small dependence on the angle to sunlight. Accordingly, the Kaiser filtering of this orientation effect are applied to derive the final temperature value, $T_{\text {fin }}$, in algorithm for IMS-100-GDP. 


\subsubsection{Relative humidity (RH)}

An overview of RH calculation is given in Fig. 4. $T_{\text {hum }}$ and $L$ are temperature of humidity sensor and length of unwinder or string, respectively. For the time-lag correction, which corrects the effect of the time constant delay, the response time coefficients are constant for the RS-11G-GDP.1, but are dependent on whether the RH sensor is absorbing or desorbing water vapor molecules (i.e., whether RH is increasing or decreasing, respectively) for the IMS-100-GDP. The trend of RH change is estimated from the slope of the tangent of $U_{0}$ using the method proposed by Savitzky and Golay (1964) using the $U_{0}$ values within \pm 5 seconds values. The response time, $\tau_{\text {hum }}$, is calculated from obtained trend value together with the temperature of the RH sensor, $T_{\text {hum }}$. For the contamination correction to filter out spike-like variations in high frequency components, an infinite impulse response (IIR) filter process is newly added to IMS-100-GDP. For hysteresis errors (i.e., the "slow-regime" in Dupont et al., 2020), they are not corrected but only considered as an uncertainty component in the RS-11G-GDP.1. For the IMS-100-GDP, the slow part ratio and its response times for absorption and for desorption are assumed as 3\%, 300 seconds and 12000 seconds, respectively. The RH of the slow part, $U_{\text {delay }}$, and the hysteresis corrected $\mathrm{RH}, U_{3}$ are derived via iterative calculation with:

$$
\begin{aligned}
U_{\text {delay }}(t) & =\frac{U_{2}(t)+(1-\alpha) \tau_{\text {hys }} U_{\text {delay }}(t-1)}{(1-\alpha) \tau_{\text {hys }}+1} \\
U_{3}(t) & =\left(1+\tau_{\text {hys }}\right) U_{\text {delay }}(t)-\tau_{\text {hys }} U_{\text {delay }}(t-1)
\end{aligned}
$$

where $\alpha$ is the slow part ratio, $\tau_{h y s}$ is the response time for the slow part and $U_{3}$ is the corrected RH.

The process of temperature-humidity-dependence (TUD) correction is same as RS-11G-GDP.1, but the coefficients are redetermined via additional chamber experiments and flight comparison results with Cryogenic Frostpoint Hygrometer (Vömel et al., 2007, 2016). The $\mathrm{T}_{\mathrm{s}} / \mathrm{T}_{\mathrm{a}}$ correction is same as RS-11G-GDP.1.

$U_{f i n}$ is the final value of RH. The uncertainty budget for RH is shown in Table 3. If $U_{f i n}+u(U)$ is less than $0 \% \mathrm{RH}$, these are treated as missing values $(\mathrm{NaN})$ in output.

\subsubsection{Geopotential height}

An overview of geopotential height calculation flow is given in Fig. 5. The raw geometric altitude, $Z_{0}$, is calculated from ellipsoidal height derived with GPS signal and the internal geoid model of iMS-100, but the grid resolution of the internal geoid model with $10^{\circ} \times 10^{\circ}$ is too coarse and the interpolated geoid height may differ from the actual geoid height by $20 \mathrm{~m}$ or more in some regions (Northwest Pacific basin including the sea near Japan is the one of the region with large differences. see Fig. 6). Accordingly, geometric altitude is recalculated using the geoid model (Pavlis et al., 2012) with a finer grid (5' $\times 5^{\prime}$ ) to derive $Z_{1}$. The results of the verification using the GNSS simulator show that $Z_{0}$ was found to have a $\simeq 1 \mathrm{~s}$ delay with respect to the assumed altitude. $Z_{1}$ is corrected for this delay to obtain $Z_{2}$. Also this verification shows that there is a delay of several seconds in measurements just after launch. This delay is attributed to Kalman filtering in positioning by the GPS module and the difference becomes negligible several seconds after launch. Accordingly, the altitude in this "transition" 
period is interpolated with the known release altitude and the observed altitude at the end of transition to obtain $Z_{3}$, which is then applied with a moving average to determine the final geometric altitude, $Z_{f i n}$. The geopotential height, $H_{f i n}$ is calculated using:

where $R$ is the radius of the earth $(6378136.0 \mathrm{~m}), g_{0}$ is standard gravity acceleration $\left(9.80665 \mathrm{~m} \mathrm{~s}^{-2}\right)$, and $g_{\phi}$ is gravity acceleration at the observation latitude.

\subsubsection{Pressure}

The iMS-100 radiosonde is not equipped with a pressure sensor. Pressure is calculated from the geopotential height, $H_{f i n}$, temperature, $T_{\text {fin }}$, and $\mathrm{RH}, U_{\text {fin }}$, using the hydrostatic equation.

\subsubsection{Wind}

An overview of wind calculation flow is given in Fig. 7. While the initial (unsmoothed) wind speed and direction are derived from GPS Doppler shift for RS-11G-GDP.1, the initial wind speed sspeed $_{0}$ and direction wdir $_{0}$ are derived as motion vectors from GPS positioning, thereby supporting longitude $(\lambda)$ and latitude $(\phi)$ for IMS-100-GDP. The great-circular distance, $d$, and direction, $\theta$, between the position at $t_{i}\left(\lambda_{i}, \phi_{i}\right)$ and $t_{i+1}\left(\lambda_{i+1}, \phi_{i+1}\right)$ are given with spherical trigonometry by:

$d=R \arccos \left(\sin \phi_{i} \sin \phi_{i+1}+\cos \lambda_{i} \cos \lambda_{i+1} \cos \left(\lambda_{i+1}-\lambda_{i}\right)\right)$

$\theta=90-\arctan \left(\frac{\cos \lambda_{i} \tan \lambda_{i+1}-\sin \phi_{i} \cos \left(\lambda_{i+1}-\lambda_{i}\right)}{\sin \left(\lambda_{i+1}-\lambda_{i}\right)}\right)$

where $R$ is the radius of the earth, and $d$ and $\theta$ are rendered as sspeed $_{0}$ and $w d i r_{0}$, respectively.Smoothing process is same as RS-11G-GDP.1. The wind vectors with a wind speed of sspeed $_{0}$ and a wind direction of $w_{d i r_{0}}$ are decomposed to the zonal and meridional wind components, $u_{0}$ and $v_{0}$. Each components are smoothed by a low-pass filter using Kaiser window with a cut-off frequency of $1 / T_{\text {pend }}$ to derive the final wind components, $u_{f i n}$ and $v_{f i n}$, respectively. The final wind components are synthesized to wind speed, wspeed $_{f i n}$, and direction, wdir $_{f i n}$.

\subsection{GRUAN data processing for RS92}

As data processing for RS92-GDP version 2 has detailed by Dirksen et al. (2014), only a brief description is provided here.

Raw temperature data are corrected for solar radiation and heat spike errors. Solar radiation errors relate to overall direct and scattered solar irradiance, ambient pressure, and ventilation, and are estimated at the GRUAN Lead Centre from a radiative transfer model that takes into account the solar elevation angle at the time of monitoring. Vaisala radiation error correction data are also available in table form. GRUAN data processing for RS92 involves application of the average of the two, as it remains unclear which the correction model is more appropriate. Heat spike errors are removed via a low-pass digital filter with a cut-off frequency of $0.1 \mathrm{~Hz}$. 
RS92 RH sensors have a temperature-dependent dry bias. GRUAN data processing corrects for this based on multiplication with an empirical correction factor before other forms of the correction are applied. Raw RH data are corrected for radiation dry bias, sensor time lag, and temperature-dependence errors. Radiation dry bias is caused by solar heating on the RH sensors, and the same approach as for the temperature sensor is used to estimate the amount of the correction required. The $\mathrm{RH}$ sensor response slows at low temperatures, and time lag becomes significant below $-40^{\circ} \mathrm{C}$. This is corrected based on the relationship between a time constant and temperature using a low-pass filter in the GRUAN data product for RS92 (Dirksen et al., 2014).

The RS92 used at Tateno has a pressure sensor and a GPS receiver, both of which can be used to calculate geopotential height. Pressure measurement data are used to derive geopotential height in the lower part of the profile where the signal-tonoise performance of the pressure sensor is sufficiently good, and measurements from the GPS sensor are used in the upper part of the profile. The altitude of the switch is typically between 9 and $17 \mathrm{~km}$ (Sommer et al., 2016). The pressure sensor is recalibrated against the reference value from a station barometer during the ground check, and calculation is performed to determine the correction factor for application to the entire pressure profile during sounding (Dirksen et al., 2014). U and V data are retrieved from the Doppler shift in the GPS carrier signal, and noise is removed using a low-pass digital filter. The smoothed data are converted into wind speed and direction values (Dirksen et al., 2014). Uncertainties of each parameters for RS92 are described in Dirksen et al. (2014).

While the authors used version 2 of the RS92 GDP, version 3 is supposed to be available in the near future (Sommer et al., 2016) and it would be useful to redo the analysis with it.

\section{Method used for dual sounding}

Dual soundings with iMS-100 and RS92 for intercomparison have been conducted from September 2017 to January 2020 at 00 UTC (09 LT; daytime) or 12 UTC (21 LT; nighttime) once a week, except for wind conditions in which a payload may fall to populated areas around metropolitan Tokyo (in general, from July to mid-September with relatively weak westerly winds in the upper troposphere due to northward displacement of the subtropical jet stream and the stratospheric easterly winds). There were 99 flights during this period (52 daytime, 47 nighttime).

Payload configuration for dual sounding is shown in Figure 8. A $1200 \mathrm{~g}$ balloon was used for all dual sounding. The iMS-100 and RS92 radiosondes were hung on both ends of a $0.9-1 \mathrm{~m}$ plastic cardboard or bamboo rod, and this rig was covered with aluminum tape to reduce the effects of radiation based on the proposal of Rohden et al. (2016).

\section{Method for comparison}

GDPs data both for iMS-100 and RS92 are collected at $1 \mathrm{~s}$ intervals. Temporally simultaneous measurements were compared using the statistical approach adopted by Kobayashi et al. (2019) to evaluate differences in the data products. 


\subsection{Screening with quality assessment}

Prior to statistical comparison, irregular or inappropriate data for comparison should be excluded. RS92-GDP, processed by the GRUAN LC, has been checked with a quality assessment algorithm by the GRUAN LC. As the algorithm for IMS-100GDP in this study is designed with reference to that for RS92-GDP, the algorithm for RS92-GDP is described before that for IMS-100-GDP.

For RS92, the first quality screening is based on differences between radiosonde and references sensor in the ground check. The thresholds are $1.5 \mathrm{hPa}$ for pressure, $1.0 \mathrm{~K}$ for temperature and $1.5 \% \mathrm{RH}$ for $\mathrm{RH}$ (Sommer, 2013). Data with larger difference are not used. The second screening is based on the uncertainty amounts (Sommer, 2013). The thresholds for uncertainty, $u_{\mathrm{spec}}^{R S 92}$, are calculated as:

$u_{\text {limit }}^{\mathrm{RS} 92}(T)=0.5$

$u_{\text {limit }}^{\mathrm{RS92}}(U)=0.025 U+2.5$

$u_{\text {limit }}^{\mathrm{RS} 92}(P)=0.0004 P+0.6$.

When uncertainties for $95 \%$ or more of data in the entire profile are within $u_{\text {limit }}$, the profile is approved and otherwise labeled as "Checked".

For RH, however, the criterion in Eq.7 is too strict, because it is lower than actual typical values especially for $50 \% \mathrm{RH}-$ $70 \%$ RH. Thus, the original formula as per Eq.9 is used here.

$u_{\text {limit }}^{\mathrm{RS92}}(U)=-0.000578 U^{2}+0.0925 U+1.457$

However, the lower limit of $u_{\text {limit }}^{\mathrm{RS} 92}(U)$ is set to $2.5 \% \mathrm{RH}$.

For iMS-100, the first screening is performed at ground check under room conditions in preparation. The thresholds of differences from reference sensors for temperature and $\mathrm{RH}$ are $\pm 0.5{ }^{\circ} \mathrm{C}$ and $7 \% \mathrm{RH}$, respectively. Sensors values exceeding these criteria are not used for observation.

The second screening checks contamination or changes in the RH sensor specifications associated with icing. In some soundings with iMS-100, abnormal RH profiles such as the one shown in Figure 9 (for 12UTC on 22 September, 2017) are sometimes observed. In this case, RH does not decrease in the stratosphere, probably due to contamination and changes in the RH sensor specifications related to icing or freezing during passage through supercooled droplet clouds. As checking to determine whether the radiosonde has passed through such clouds is impractical from the RH profile, ice saturated regions (pink shaded layer in Fig. 9(b)) are considered. However, as not all data associated with ice-saturated clouds passage are contaminated, the length of the ice-supersaturated region (ISSR) and the RH and water vapor mixing ratio at the top of the 
upper troposphere and lower stratosphere (UTLS) are used for screening in this study. ISSR determination is based on saturated water vapor for liquid water and ice calculated using Hyland and Wexler equation (Hyland and Wexler, 1983). The observed $\mathrm{RH}$ is the ratio of water vapor pressure to $e_{\mathrm{s}_{-} \text {liq }}$, and is limited to $U_{\mathrm{s}_{-} \text {ice }}=e_{\text {sat_ice }} / e_{\text {sat_liq }}$ for the ice phase. Accordingly, ISSR

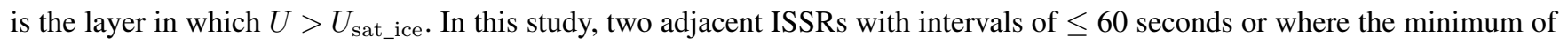
$U-U_{\text {sat_ice }}$ is more than $-10 \% \mathrm{RH}$ (i.e., with no dry layer in the interval) are merged and treated as a single ISSR.

For screening of ice-contaminated profiles, the probability of icing, $P r_{\text {ice, }}$, is derived via logistic regression using 452 training routine observations with a single payload taken from April to November 2018. $P r_{\text {ice }}$ is calculated with:

$$
P r_{i c e}=\frac{1}{1+\exp \left(-22.38+7.18 \times 10^{-3} T_{\mathrm{ISSR} \_ \text {max }}+0.517 U_{\mathrm{ST} 1}+0.977 U_{\mathrm{ST} 2}+0.105 W_{\mathrm{ST} 1}+0.427 W_{\mathrm{ST} 2}\right)}
$$

where ST1 and ST2 are data points at $2000 \mathrm{~m}$ and $4000 \mathrm{~m}$ above the tropopause in geopotential height, $U$ [\% RH] is $\mathrm{RH}, W$ [ppmv] is the water vapor volume mixing ratio, and $T_{\mathrm{ISSR} \_ \text {max }}$ is the pass-through period of maximum ISSR. In this study, profiles with $P r_{\text {ice }}>0.5$ are considered as potentially ice-contaminated data and excluded in the RH analysis below.

The third screening is based on uncertainties for temperature, RH and pressure as with RS92. The thresholds for these values are derived from Eqs.11 - 13, respectively. Coefficients are determined empirically.

$u_{\text {limit }}^{\mathrm{iMS}}(T)=0.7$

$u_{\text {limit }}^{\mathrm{iMS}}(P)=1.609 \times 10^{-9} P^{3}-4.589 \times 10^{-6} P^{2}+4.120 \times 10^{-3} P+3.810 \times 10^{-2}$.

The ratio criterion is set to $90 \%$. It should be noted that this quality assessment and screening are only for this study only, and are not authorized as standard for GDPs. The standard method for quality assessment of GDPs is currently under discussion by the quality task force in the GRUAN community.

Dual sounding data for 57 flights (27 daytime and 30 nighttime; Table 4) are used for comparison. The major factors associated with data screening is illustrated in Fig. 10 for each season and daytime/nighttime. Seasonal profiles for temperature, RH, and wind speed are shown in Figs. 11 - 13, with seasonal classification (MA, MJJ, ASON and DJF) described in Sect. 4.4.

\subsection{Timestamp adjustment}

Radiosonde observation have timestamps from the relevant sounding system (for iMS-100, this is based on received GPS clock data). As there may be minor discrepancies in balloon-launch time stamps, these data are time-adjusted using the temperature profile. In this study, shift registration in functional data (Ramsay and Silverman, 2005) is used for adjustment using the temperature data from between 5 and 20 minutes of the launch time of RS92. Temperature data for each radiosonde, $T_{i}(t)$, in 
this period are converted to functional data, $x_{i}(t)$. Shift values, $\delta_{i}$, are calculated to minimize the least squares of $x_{i}\left(t+\delta_{i}\right)$, i.e.,

REGSEE $=\sum_{i} \int\left[x_{i}\left(t+\delta_{i}\right)-\hat{\mu}(t)\right]^{2} d s$

where $\hat{\mu}(t)$ is the mean function of $x_{i}(t)$. For calculation of $\delta_{i}$, the scikit-fda package (Carreño, 2020) for python is used and actual adjustment values (seconds to shift) are derived with

$\delta t=\delta t_{\mathrm{RS} 92}-\delta t_{\mathrm{iMS}}$

When $\delta t>0$, timestamps for iMS-100 are shifted backward by $|\delta t|$, and vice versa.

\subsection{Data pretreatment}

Profiles with $>90 \%$ of abnormal data points as whole profile are excluded via screening as described in Section 4.1, while abnormal data are also seen at individual points in overall normal profiles (e.g, superadiabatic lapse rates). Such data points should be excluded from statistical comparison. In this study, superadiabatic lapse rate layers and abnormal wind data immediately before balloon burst are pre-treated for masking.

\subsection{Statistical comparison}

After timestamp adjustment, per-second differences between iMS-100 and RS92 measurements were calculated and differences were allocated to the 13 pressure layers based on RS92 pressure data ( $P_{i}^{\mathrm{RS} 92}$, where $i$ indicates the time step) based on Kobayashi et al. $(2012,2019)$. The bins for the 13 layers are listed in Table 5.

$A_{i, j}^{\mathrm{iMS}}$ and $A_{i, j}^{\mathrm{RS} 92}$ are values at the time step $i$ for iMS-100 and RS92 in the $j$ th dual sounding data set $(j=1, \ldots, M ; M$ in the number of data sets), respectively. The differences between the two radiosonde types, $\Delta A_{i, j}=A_{i, j}^{\mathrm{iMS}}-A_{i, j}^{\mathrm{RS} 92}$, are averaged for each pressure layer with:

$\overline{\Delta A_{k, j}}=\frac{\sum_{i=i_{b, j}}^{i_{t, j}} \Delta A_{i, j}}{N_{k, j}}$

where $k$ is the layer number $(k=1, \ldots, 13), N_{k, j}$ is the number of data points in the layer $k, i_{b, j}$ and $i_{t, j}$ are the bottom and top time step at the $j$ th data set, respectively. The ensemble mean of the difference in each pressure layer is calculated as

$\left\langle\Delta A_{k}\right\rangle=\frac{\sum \overline{\Delta A_{k, j}}}{M}$.

The standard deviation of the ensemble mean difference for individual pressure layers is

$\sigma\left(A_{k}\right)=\sqrt{\frac{\sum_{j=1}^{M}\left(\overline{\Delta A_{k, j}}-\left\langle\Delta A_{k}\right\rangle\right)}{M}}$

Comparison of wind data is performed with the indices of the wind speed bias, $B I A S$, and the root mean square error the vector difference, RMSVD (CGMS, 2003) for each pressure layer at each dual sounding. BIAS, MVD and RMSVD are 
calculated as

$B I A S_{k, j}=\sum \frac{1}{N}\left(V_{i, j}^{i M S}-V_{i, j}^{R S 92}\right)$

$V D_{i, j}=\sqrt{\left(u_{i, j}^{\mathrm{iMS}}-u_{i, j}^{\mathrm{RS} 92}\right)^{2}+\left(v_{i, j}^{\mathrm{iMS}}-v_{i, j}^{\mathrm{RS} 92}\right)^{2}}$

260

$M V D_{k, j}=\frac{1}{N_{k, j}} \sum V D_{i, j}$

$S D_{k, j}=\sqrt{\frac{1}{N_{k, j}} \sum\left(V D_{i, j}-M V D_{k, j}\right)^{2}}$

$R M S V D_{k, j}=\sqrt{M V D_{k, j}^{2}+S D_{k, j}^{2}}$

where $V, u$, and $v$ is the wind speed, zonal wind speed and meridional wind speed, respectively. The mean difference of wind direction (Szantai et al., 2007), $\overline{\Delta D I R}$, is also used.

$\overline{\Delta D I R_{k, j}}=\frac{180}{N \pi} \sum \arccos \left(\frac{\boldsymbol{V}_{i, j}^{i M S} \cdot \boldsymbol{V}_{i, j}^{R S 92}}{V_{i, j}^{i M S} V_{i, j}^{R S 92}}\right)$

where $\boldsymbol{V}$ is the wind vector. The ensemble mean of these parameters is then calculated as for Eq.17.

Statistics for each pressure layer are calculated for daytime, nighttime, and individual seasons. Due to the safety consideration described in Section 3, few dual soundings are performed in July and August, and the weather conditions for August flights are categorized as for autumn rather than summer. Thus, in this study, the flights from August to November are categorized as those for autumn (here, ASON), and previous studies for seasonal comparison campaigns of radiosondes at Tateno (Kobayashi, 2015; Kobayashi and Hoshino, 2018), the "summer" covered the period from May to June, flights in March and April are categorized with spring (here, MA), those from May to July are categorized with summer (MJJ), and those from December to February are categorized with winter (DJF).

\subsection{Method for verification of consistency with uncertainties}

Uncertainty estimation for RS92 and iMS-100 GDPs are described in Dirksen et al. (2014) and Hoshino et al. (2021), respectively. The statistical consistency check considering uncertainties is performed based on Immler et al. (2010) and Sect. 5 in Kobayashi et al. (2019). 


\section{Results}

\subsection{Temperature}

Figure 14 shows the ensemble mean (lines) and standard deviation (error bar) of temperature differences, for (a) daytime and nighttime for all season, (b) seasonal daytime, and (c) seasonal nighttime. In the stratosphere, IMS-100-GDP value are around $0.5 \mathrm{~K}$ lower than RS92-GDP for the daytime. For the nighttime, differences are around $-0.1 \mathrm{~K}$ below the $10 \mathrm{hPa}$ level. Seasonal differences are small.

Figure 15 shows the percentage of consistency rank in each layer for (a) daytime and (b) nighttime. The percentages of significantly different or inconsistent data exceed $50 \%$ in L07 (100 - $70 \mathrm{hPa}), 30 \%$ in L08 (70 - 50 hPa) and L09 (50 - 30 $\mathrm{hPa}$ ) for daytime observation (Fig 15(a)). However, $80 \%$ of data are in agreement for nighttime comparison (Fig 15(b)). Fig. 16 shows the distribution of temperature at L09 (50 - 30 hPa), L07 (100 - $70 \mathrm{hPa}), \mathrm{L} 05$ (200 - $150 \mathrm{hPa})$ and L03 (500 - 300 hPa). Fig. 16 (a1), (a2) and (a3) show differences in L09, L07 and L05 in general are normally distributed with a sufficient sample size. Accordingly, daytime temperature differences in the stratosphere and the upper troposphere are associated with systematic effects. These differences (especially between 100 and $30 \mathrm{hPa}$ ) are attributed to difference in the solar radiation correction models. However, some samples show significant differences $(> \pm 0.5 \mathrm{~K})$ even in the troposphere or for nighttime soundings (not shown), which are associated either with issues during flights or calibration problems.

Kobayashi et al. (2019) found that the RS-11G-GDP.1 temperature data are about -0.4 K lower than RS92-GDP.2 data for daytime observations in the stratosphere. This means that the IMS-100-GDP temperatures show larger differences from RS92-GDP.2 than RS-11G-GDP.1 temperatures do. On the other hand, the ratio of data that are evaluated as "consistent" or "in agreement" with RS92-GDP.2 temperatures is greater for IMS-100-GDP than RS-11G-GDP.1. This is probably due to the newly included correction for the sensor orientation effects in IMS-100-GDP. Further investigation is needed using intercomparison results between RS-11G and iMS-100 radiosondes.

The GDPs for Vaisala RS41 radiosonde (Rohden et al., 2021) and for Meteomodem M10 radiosonde (Dupont et al., 2020) and an upgraded of GDP for RS92 are currently under development. Also, the WMO 2022 Upper-Air Instrument Intercomparison Campaign (CIMO Task Team on Upper-air Intercomparison, 2020) is being planned in 2022. These upcoming GDPs and the results from the WMO intercomparison campaign are expected to be useful for further evaluation of IMS-100-GDP.

\subsection{Relative humidity}

Figure 17 shows the ensemble mean (lines) and standard deviation (error bars) of RH differences, for (a) daytime and nighttime for all seasons, (b) seasonal daytime and (c) seasonal nighttime. This shows that iMS-100 RH is around $1-2 \% \mathrm{RH}$ larger than RS92 RH around the tropopause and $-1 \% \mathrm{RH}$ smaller in the stratosphere. Unlike temperature, differences between daytime and nighttime soundings are small but seasonal variations are large in the upper troposphere and the lower stratosphere. Figure 18 shows the ensemble mean of RH differences for six RH ranks. In the lower troposphere (below $500 \mathrm{hPa}$ level), differences are around $1 \% \mathrm{RH}$ and exhibit limited correspondence with RH values. In the middle and upper troposphere (500 - $100 \mathrm{hPa})$, the difference increases with altitude for $10-90 \% \mathrm{RH}$. For data with $\mathrm{RH} \leq 10 \% \mathrm{RH}$, the difference is within $\pm 1 \% \mathrm{RH}$ for 
all layers; iMS-100 RH is wetter in the troposphere and drier in the stratosphere. For data with RH $>90 \% \mathrm{RH}$, the dataset is limited above $300 \mathrm{hPa}$ and drier than RS92 figures for the middle troposphere $(500-300 \mathrm{hPa})$.

Kobayashi et al. (2019) found that RS-11G-GDP.1 RH data shows about $2 \%$ RH dry tendencies for conditions with RH $>$ $90 \% \mathrm{RH}$ and about $1 \% \mathrm{RH}$ wet tendencies for conditions with $\mathrm{RH} \leq 10 \% \mathrm{RH}$. These different behaviors between of RS-11GGDP.1 and IMS-100-GDP with respect to RS92-GDP.2 in very dry and very wet conditions make the $\Delta U$ profiles different in the lower troposphere (below $700 \mathrm{hPa}$ ) and in the stratosphere (above $50 \mathrm{hPa}$ ) (See Fig.17 in this study and Fig. 11 of Kobayashi et al., 2019). In particular, the $1 \%$ RH wet bias of RS-11G-GDP.1 with respect to RS92-GDP.2 and the dry bias of IMS-100-GDP in the stratosphere are a notable differences. The major reason of these differences would be the including of hysteresis correction in the IMS-100-GDP. The ratio of data that are evaluated as "consistent" or "in agreement" with RS92GDP.2 RH data in the troposphere is greater for RS-11G-GDP.1. This is also due to the inclusion of hysteresis correction in the IMS-100-GDP, because the RH profiles in the troposphere often show rapid changes as shown in Fig.12. Further investigation on the differences between RS-11G and iMS-100 results by making intercomparison flights is a future task.

Figure 19 shows the percentage of consistency rank in each layer for (a) daytime and (b) nighttime. In the troposphere and lower stratosphere (L1 - L7, below $70 \mathrm{hPa}$ level), around $10-20 \%$ of data are significantly different or inconsistent. The RH profiles for individual flights (Fig. 12) show that RH often shows rapid changes. For the flight at 12 UTC (21 LT) on 19 April, 2019 (Fig. 20), iMS-100 shows a slow tendency in relation to the rapid decrease in RH (e.g., at about $330 \mathrm{hPa}$ ), compared to RS92. This difference in response to rapid changes is considered a reason for the inconsistency of 1-second RH values between the two radiosondes. In the stratosphere (L8 - L13, above the $70 \mathrm{hPa}$ level), RH data from iMS-100 and RS92 seem to be almost in agreement.

\subsection{Pressure}

Figure 21 shows the ensemble mean (lines) and standard deviation (error bars) of pressure differences for (a) daytime and nighttime for all season, (b) seasonal daytime, and (c) seasonal nighttime. The absolute value of ensemble mean difference is less than $0.4 \mathrm{hPa}$, but there are cases with large differences in the lower troposphere (below $700 \mathrm{hPa}$ level). This may be attributable to the effect of pressure differences between RS92 pressure sensor and the barometer used for surface observation. The pressure of IMS-100, with no pressure sensor, is derived from recursive calculation via the hydrostatic equation, so that the surface pressure is equal to that observed using ground-based barometer. Meanwhile, RS92 involves independent pressure sensor usage, meaning that near-surface pressure may differ between GDPs. A histogram of RS92 GDP surface pressure error for ground-based barometer content (Fig. 22) shows that the difference is not normally distributed around zero. RS92 pressure tends to be slightly higher than ground-based barometer content with a difference median of $0.33 \mathrm{hPa}$, which is greater than barometer uncertainty $(0.06 \mathrm{hPa})$. The effect of this difference decreases with height, but is more noticeable near the ground.

For RS-11G-GDP.1, the pressure is about $-0.5 \mathrm{hPa}$ lower for daytime observation in middle of troposphere, but the difference between IMS-100-GDP and RS92-GDP.2 is little in those layer statistically. At this time, the reason of this difference of pressure is not clear. 


\subsection{Geopotential height}

Figure 23 shows the ensemble mean (lines) and standard deviation (error bars) of geopotential height differences, for (a) daytime and nighttime for all seasons, (b) seasonal daytime, and (c) seasonal nighttime. The difference in geopotential height is around $2-3 \mathrm{~m}$ in the lower and middle troposphere, but becomes larger with altitude above $100 \mathrm{hPa}$ level and become about $10 \mathrm{~m}$ at $20 \mathrm{hPa}$. This tendency is attributed to difference in geoid height as referenced by IMS-100-GDP and RS92GDP. As described in Section 2.2.3, the grid size of the original geoid model used for the iMS-100 GPS module is $10^{\circ} \times 10$ ${ }^{\circ}$, which is replaced with a $5^{\prime} \times 5^{\prime}$ model for geometric height calculation in GDP processing. The grid size difference causes significant discrepancy in geoid and geometric height especially for the northwest Pacific basin around Japan. Figures 24(a) and (b) show geoid height for IMS-100-GDP and original iMS-100, respectively, 24(c) shows differences in geoid height and typical radiosonde track for each season (green for MA, red for MJJ, orange for ASON and blue for DJF), and 24(d) shows geoid correction values for typical seasonal tracks. The difference increases with height for all seasons. The grid size of the geoid model for RS92-GDP is unknown but as geometric height values are used without modification, geoid model differences may have caused geopotential height differences.

The geopotential height difference between IMS-100-GDP and RS92-GDP.2 seems to have no noticeable different with that between RS-11G-GDP.1 and RS92-GDP.2, although the RS-11G-GDP.1 is not corrected geoid model. This implies that the geoid model used in RS-11G has enough resolution for GDP.

\subsection{Wind}

Figure 25 compares wind for (a) wind speed bias, (b) RMSVD and (c) wind direction difference for all seasons. The difference is small enough with BIAS from -0.15 to $+0.01 \mathrm{~m} \mathrm{~s}^{-1}$, RMSVD is less than $0.72 \mathrm{~m} \mathrm{~s}^{-1}$ except for L13 (above $10 \mathrm{hPa}$ ), and $\overline{\triangle D I R}$ is less than $5^{\circ}$.

\section{Comparison with a frost-point hygrometer}

Due to the technical limitations of the RH sensors mounted on operational radiosondes in low temperature and dry conditions, GRUAN requires comparisons of RH data with values from reference instruments. At Tateno, the comparison flights with radiosondes and cryogenic frostpoint hygrometer (CFH; Vömel et al., 2007, 2016) have been conducted twice a year since 2015. However, since the R-23 (HFC-23) liquid cryogen material used to cool the mirror of CFH was regulated under the Montreal Protocol, a new frost-point hygrometer, Meisei SKYDEW (Sugidachi, 2019) was adopted in 2020 for cooling the mirror with a Peltier element instead. Figure 26 shows results from the comparison conducted at 06 UTC (15 LT) on 21 October 2020. Although the difference in RH are significant (with $\Delta U$ exceeding the extended uncertainty $(k=2)$ ) in the limited part 375 around the tropopause $\left(17041.6 \mathrm{~m}, 92.2 \mathrm{hPa}\right.$ and $\left.-73.4^{\circ} \mathrm{C}\right)$, Fig. 26(c) shows that the RH of IMS-100-GDP and SKYDEW are generally in agreement for the entire profile and consistent for most of the troposphere. 


\section{Summary}

To characterize GDPs for iMS-100 and RS92, data from dual soundings conducted at Tateno from September 2017 to January 2020 are analyzed in this study. The iMS-100 temperature is around $0.5 \mathrm{~K}$ lower than RS92-GDP for daytime observation in the stratosphere and over $50 \%$ of data from between 100 and $70 \mathrm{hPa}$ and over $30 \%$ from between $70 \mathrm{hPa}$ and $30 \mathrm{hPa}$ shows significant differences from RS92-GDP. For nighttime observation, the difference is around $-0.1 \mathrm{~K}$ with over $80 \%$ of data showing in agreement both in the troposphere and the stratosphere. The difference for daytime measurements in the stratosphere is attributed to the correction procedures for solar radiation heating and differences in sensor characteristics.

The iMS-100 RH is around $1-2 \% \mathrm{RH}$ higher in the troposphere and $1 \% \mathrm{RH}$ lower in the stratosphere than RS92, but both GDPs are generally in agreement in the troposphere and stratosphere. The difference may be larger in places where rapid RH change occurs. A comparison flight with the SKYDEW, frost-point hygrometer, shows that iMS-100 RH agrees well with SKYDEW both in the troposphere and stratosphere.

While there are some cases with significant differences are observed in the lower troposphere $(\geq 700 \mathrm{hPa})$, the mean pressure difference is less than $0.4 \mathrm{hPa}$. The difference in geopotential height is around $2-3 \mathrm{~m}$ in the lower and middle troposphere, but increases with altitude above $100 \mathrm{hPa}$ level, from $10 \mathrm{~m}$ at $20 \mathrm{hPa}$. This relationship between height and related differences may stem from differences in the geoid model used for the two GDPs. In wind comparison, BIAS is between -0.15 and +0.01 $\mathrm{m} \mathrm{s}^{-1}$, RMSVD is lower than $0.72 \mathrm{~m} \mathrm{~s}^{-1}$ except for above $10 \mathrm{hPa}$, and $\overline{\Delta D I R}$ is smaller than $5^{\circ}$, showing good GDP correspondence.

The modified data processing described in Sect. 2.2.1 - 2.2.2 will be implemented to processing for RS-11G to create new version of RS-11G-GDP, which will be evaluated with intercomparison campaigns written in Kobayashi et al. (2019) (RS-11G and RS92) and Kobayashi and Hoshino (2018) (iMS-100 and RS-11G). Further direct comparison between RS-11G-GDP and IMS-100-GDP will be discussed in the future study.

This study involved evaluation of the characteristics of IMS-100-GDP values with RS92-GDP as a reference, as the latter is certified as a GRUAN data product. GRUAN certification for iMS-100 is underway, and ongoing analysis of GDP data is considered important for the provision of high-quality products to the climate research/monitoring community. Since February 2020, regular dual soundings of iMS-100 and Vaisala RS41 (the successor to RS92), have been ongoing. RS41-GDP is under development (Rohden et al., 2021) and the comparison results will be published when sufficient IMS-100-GDP and RS41-GDP data available. In addition, IMS-100-GDP, RS41-GDP and M10-GDP (Dupont et al., 2020) are also candidates of the reference data in the WMO 2022 Upper-Air Instrument Intercomparison Campaign (CIMO Task Team on Upper-air Intercomparison, 2020) which will be conducted in 2022. These data will support further evaluation and improvement of IMS-100-GDP.

Data availability. The GRUAN data products for RS92-GDP.2 are available from https://doi.org/10.5676/GRUAN/RS92-GDP.2 (Sommer et al., 2012). Further data are available upon request. 
https://doi.org/10.5194/amt-2021-374

Atmospheric

Preprint. Discussion started: 23 February 2022

(c) Author(s) 2022. CC BY 4.0 License.

(c) (1)

\section{Appendix A: Abbreviations}

EPS Expanded Polystyrene Styrofoam

GBAS Ground-Based Augmentation System

GCOS Global Climate Observing System

GDP GRUAN Data processing

GMDB GRUAN Meta DataBase

GNSS Global Navigation Satellite System

415 GPS Global Positioning System

GRUAN GCOS Reference Upper Air Network

JMA Japan Meteorological Agency

JFMT JMA transmission Format

LC Lead Centre

Meisei Meisei Electric Co., LTD

NCEI NOAA National Centers for Environmental Information

RH Relative humidity

RMSVD Root mean square of vector difference

SBAS Satellite-Based Augmentation System

WMO World Meteorological Organization

Author contributions. SH, TS, KS, and EK developed the iMS-100 GRUAN data product, with SH and EK performing data analysis and creating the figures. All authors provided ideas and contributed to interpretation of the results. The first draft of the paper was written by SH, with all authors contributing to improvement of the paper.

Acknowledgements. The authors are grateful to the Aerological Observatory, the Observation Division of JMA's Atmosphere and Ocean Department, and Meisei Electric for their support and helpful advice. Thanks are also due to GRUAN Lead Centre staff for their support. 
https://doi.org/10.5194/amt-2021-374

Preprint. Discussion started: 23 February 2022

(c) Author(s) 2022. CC BY 4.0 License.
Atmospheric

Measurement

Techniques

Discussions

\section{References}

Bodeker, G. E., Bojinski, S., Cimini, D., Dirksen, R. J., Haeffelin, M., Hannigan, J. W., Hurst, D. F., Leblanc, T., Madonna, F., Maturilli, M., Mikalsen, A. C., Philipona, R., Reale, T., Seidel, D. J., Tan, D. G. H., Thorne, P. W., Vömel, H., and Wang, J.: Reference Upper-Air Observations for Climate: From Concept to Reality, BAMS, 97, 123-135, https://doi.org/10.1175/bams-d-14-00072.1, 2016.

Carreño, C. R.: GAA-UAM/scikit-fda, https://doi.org/10.5281/zenodo.3957915, 2020.

CGMS: Consolidated report of CGMS activities (10th edition, V10), Tech. rep., The Coordination Group for Meteorological Satellites (CGMS), http://www.cgms-info.org/documents/consolidated-report-of-cgms-activities-\%282003\%29.pdf, 2003.

CIMO Task Team on Upper-air Intercomparison: Project Plan for the WMO Upper-Air Instrument Intercomparison, 2020.

Dirksen, R. J., Sommer, M., Immler, F. J., Hurst, D. F., Kivi, R., and Vömel, H.: Reference Quality Upper-Air Measurements: GRUAN Data

Processing for the Vaisala RS92 Radiosonde, Atmos. Meas. Tech., 7, 4463-4490, https://doi.org/10.5194/amt-7-4463-2014, 2014.

Dupont, J.-C., Haeffelin, M., Badosa, J., Clain, G., Raux, C., and Vignelles, D.: Characterization and Corrections of Relative Humidity Measurement from Meteomodem M10 Radiosondes at Midlatitude Stations, Journal of Atmospheric and Oceanic Technology, 37,857 871, https://doi.org/10.1175/JTECH-D-18-0205.1, https://journals.ametsoc.org/view/journals/atot/37/5/jtech-d-18-0205.1.xml, 2020.

Hoshino, S., Sugidachi, T., Shimizu, K., Iwabuchi, M., and Fujiwara, M.: Technical Characteristics and GRUAN Data Processing for the

Meisei RS-11G and iMS-100 Radiosondes, GRUAN Technical Document 5 (Rev. 2.0), GRUAN Lead Centre, 2021.

Hyland, R. and Wexler, A.: Formulations for the Thermodynamic Properties of the Saturated Phases of $\mathrm{H}_{2} \mathrm{O}$ from $173.15 \mathrm{~K}$ to $473.15 \mathrm{~K}$, ASHRAE Trans., 89, 500-519, 1983.

Immler, F. J., Dykema, J., Gardiner, T., Whiteman, D. N., Thorne, P. W., and Vömel, H.: Reference Quality Upper-Air Measurements: Guidance for Developing GRUAN Data Products, Atmos. Meas. Tech., 3, 1217-1231, https://doi.org/10.5194/amt-3-1217-2010, 2010.

Kizu, N., Sugidachi, T., Kobayashi, E., Hoshino, S., Shimizu, K., Maeda, R., and Fujiwara, M.: Technical Characteristics and GRUAN Data Processing for the Meisei RS-11G and iMS-100 Radiosondes, GRUAN Technical Document 5, GRUAN Lead Centre, 2018.

Kizu, N., Sugidachi, T., Kobayashi, E., Hoshino, S., Shimizu, K., Maeda, R., and Fujiwara, M.: RS-11G GRUAN Data Product Version 1, https://doi.org/10.5676/GRUAN/RS-11G-GDP.1, 2019.

Kobayashi, E.: Quantitative comparison of the Meisei RS-11G radiosonde and the Vaisala RS92-SGP radiosonde for characterization of routine soundings, Journal of the Aerological Observatory, 73, 11-24, 2015.

Kobayashi, E. and Hoshino, S.: Quantitative comparison of the iMS-100 and the RS-11G GPS sondes for characterization of routine soundings, Journal of the Aerological Observatory, 75, 17-38, 2018.

Kobayashi, E., Noto, Y., Wakino, S., Yoshii, H., Ohyoshi, T., Saito, S., and Baba, Y.: Comparison of Meisei RS2-91 Rawinsondes and Vaisala RS92-SGP Radiosondes at Tateno for the Data Continuity for Climatic Data Analysis, Journal of the Meteorological Society of Japan. Ser. II, 90, 923-945, https://doi.org/10.2151/jmsj.2012-605, 2012.

Kobayashi, E., Hoshino, S., Iwabuchi, M., Sugidachi, T., Shimizu, K., and Fujiwara, M.: Comparison of the GRUAN Data Products for Meisei RS-11G and Vaisala RS92-SGP Radiosondes at Tateno (36.06N, 140.13E), Japan, amt, 12, 3039-3065, https://doi.org/10.5194/amt-123039-2019, 2019.

Meisei Electric Co., Ltd.: GPS Radiosonde iMS-100, https://archive.meisei.co.jp/english/products/ims-100-e.pdf, 2020.

Pavlis, N. K., Holmes, S. A., Kenyon, S. C., and Factor, J. K.: The Development and Evaluation of the Earth Gravitational Model 2008 (EGM2008), Journal of Geophysical Research: Solid Earth, 117, https://doi.org/10.1029/2011JB008916, 2012. 
Ramsay, J. O. and Silverman, B. W.: The Registration and Display of Functional Data, in: Functional Data Analysis, pp. 127-145, Springer New York, New York, NY, https://doi.org/10.1007/0-387-22751-2_7, 2005.

Rohden, von, C., Sommer, M., and Dirksen, R.: Rigging Recommendations for Dual Radiosonde Soundings, GRUAN Technical Note 7, GRUAN Lead Centre, Lindenberg, 2016.

Rohden, von, C., Sommer, M., Naebert, T., Motuz, V., and Dirksen, R. J.: Laboratory Characterisation of the Radiation Temperature Error of Radiosondes and Its Application to the GRUAN Data Processing for the Vaisala RS41, Atmos. Meas. Tech. Discuss., 2021, 1-36, https://doi.org/10.5194/amt-2021-187, 2021.

Savitzky, A. and Golay, M. J. E.: Smoothing and Differentiation of Data by Simplified Least Squares Procedures., Analytical Chemistry, 36, 1627-1639, https://doi.org/10.1021/ac60214a047, 1964.

Seidel, D. J., Berger, F. H., Immler, F., Sommer, M., Vömel, H., Diamond, H. J., Dykema, J., Goodrich, D., Murray, W., Peterson, T., Sisterson, D., Thorne, P., and Wang, J.: Reference Upper-Air Observations for Climate: Rationale, Progress, and Plans, Bulletin of the American Meteorological Society, 90, 361-369, https://doi.org/10.1175/2008BAMS2540.1, 2009.

Sommer, M.: GRUAN Data Flow and RS92 Data Product V2, in: 5th GRUAN Implementation and Coordination Meeting, De Bilt, Netherlands, https://www.gruan.org/gruan/editor/documents/meetings/icm-5/pres/pres_205_Sommer.pdf, 2013.

Sommer, M., Dirksen, R., and Immler, F.: RS92 GRUAN Data Product Version 2, https://doi.org/10.5676/GRUAN/RS92-GDP.2, 2012.

Sommer, M., Dirksen, R., and Rohden, von, C.: Brief Description of the RS92 GRUAN Data Product (RS92-GDP), GRUAN Technical Document 4 (Rev. 2.0), GRUAN Lead Centre, 2016.

Sugidachi, T.: Meisei SKYDEW Instrument: Analysis of Results from Lindenberg Campaign, in: GRUAN ICM-11, Singapore, 2019.

485 Szantai, A., Mémin, E., Cuzol, A., Papadakis, N., Héas, P., Wieneke, B., Alvarez, L., Becker, F., and Lopes, P.: Comparison of MSG dense atmospheric motion vector fields produced by different methods, in: 2007 EUMETSAT Meteorological Satellite Conference/15th AMS Satellite Meteorology \& Oceanography Conference, EUMETSAT, 2007.

Vaisala Oyj.: Vaisala Radiosonde RS92-SGP, https://www.vaisala.com/sites/default/files/documents/RS92SGP-Datasheet-B210358EN-FLOW.pdf, 2013.

Vömel, H., David, D. E., and Smith, K.: Accuracy of Tropospheric and Stratospheric Water Vapor Measurements by the Cryogenic Frost Point Hygrometer: Instrumental Details and Observations, JGRA, 112, D08 305, https://doi.org/10.1029/2006jd007224, 2007.

Vömel, H., Naebert, T., Dirksen, R., and Sommer, M.: An Update on the Uncertainties of Water Vapor Measurements Using Cryogenic Frost Point Hygrometers, AMT, 9, 3755-3768, https://doi.org/10.5194/amt-9-3755-2016, 2016. 


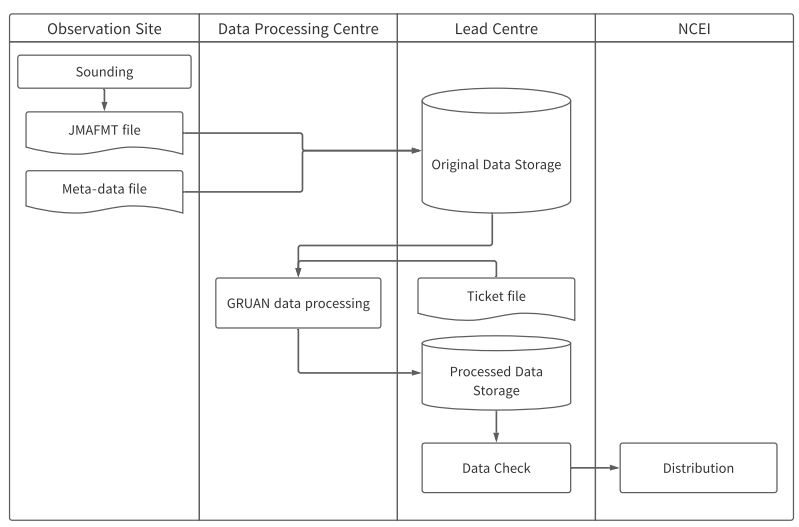

Figure 1. GRUAN data files stream

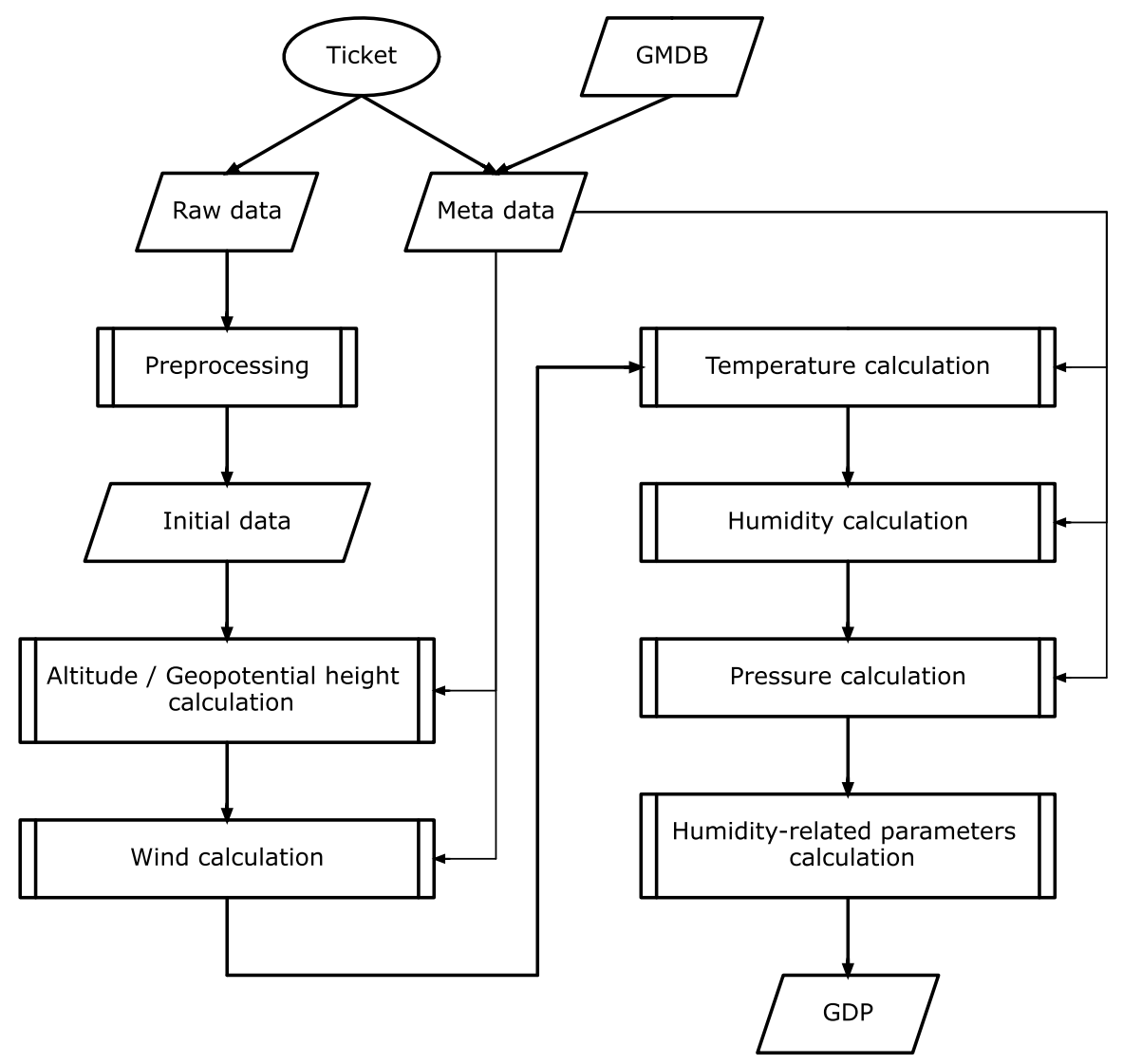

Figure 2. GRUAN data processing for iMS-100 (GMDB: GRUAN Meta Database) 


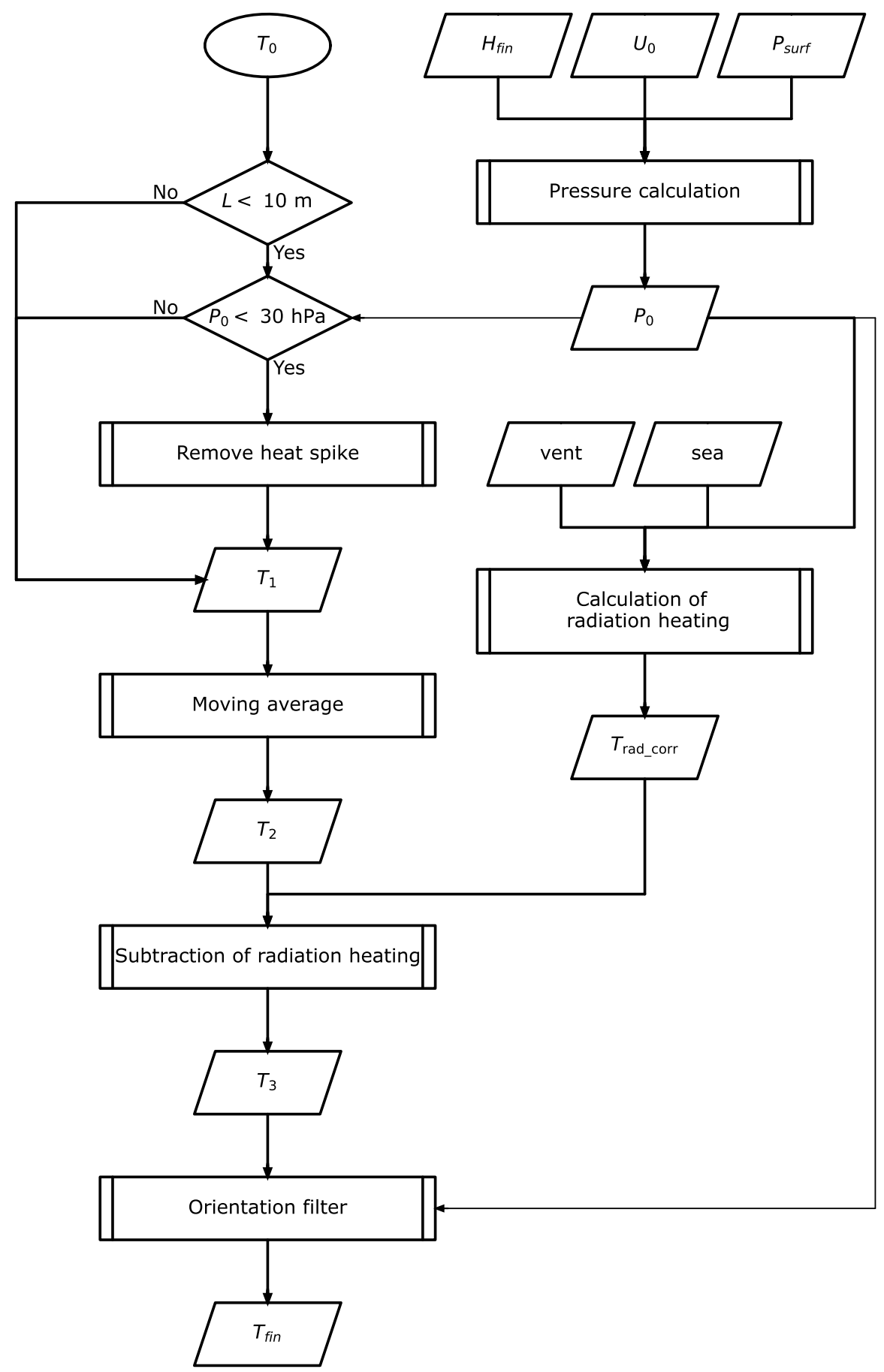

Figure 3. Temperature processing for iMS-100 (L: the total string (or unwinder) length; sea: sun elevation angle derived from time and radiosonde position) 
https://doi.org/10.5194/amt-2021-374

Preprint. Discussion started: 23 February 2022

(c) Author(s) 2022. CC BY 4.0 License.
Atmospheric Measurement

Techniques

Discussions

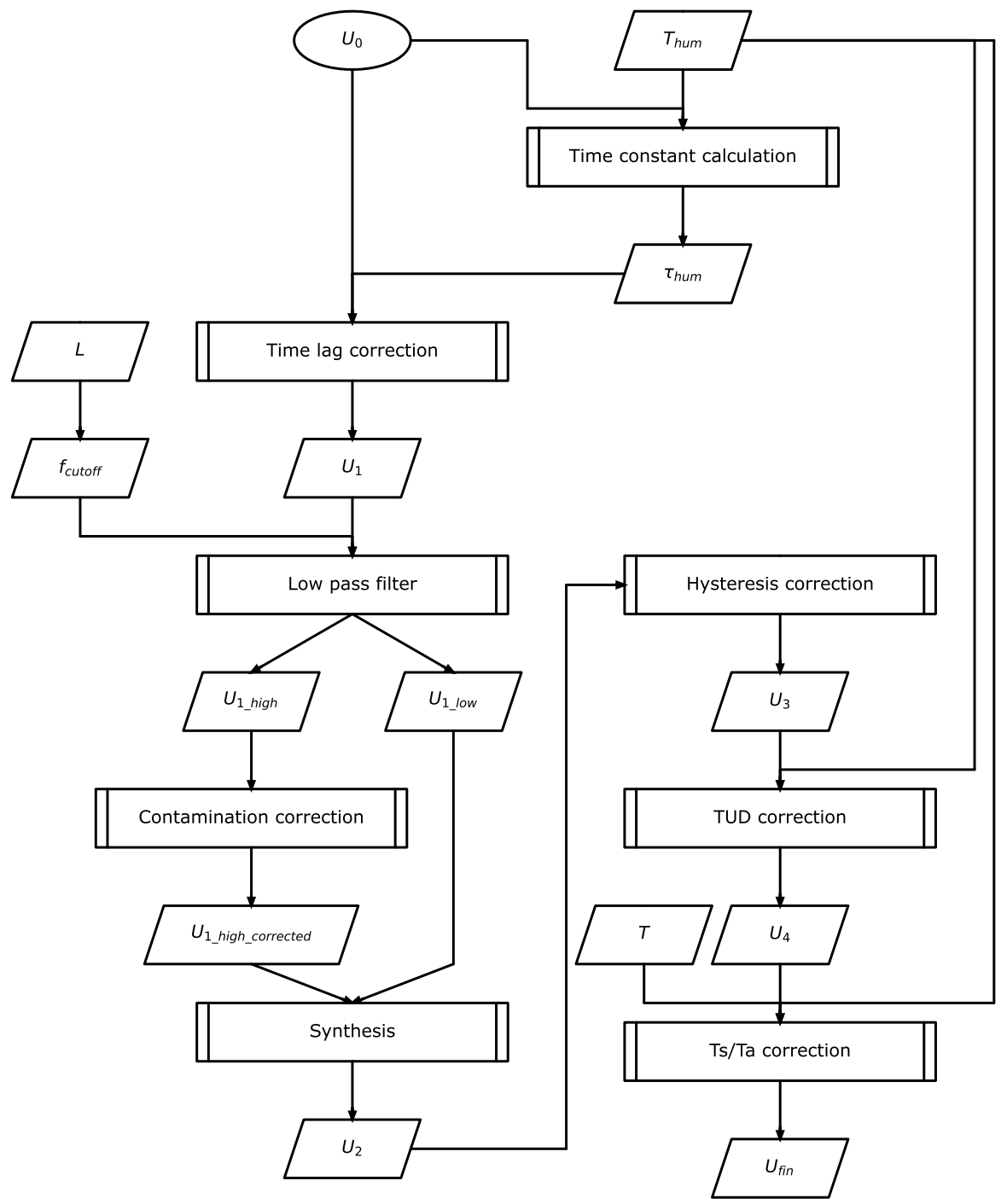

Figure 4. As per Fig.3, but for RH 
https://doi.org/10.5194/amt-2021-374

Preprint. Discussion started: 23 February 2022

(c) Author(s) 2022. CC BY 4.0 License.
Atmospheric Measurement

Techniques

Discussions

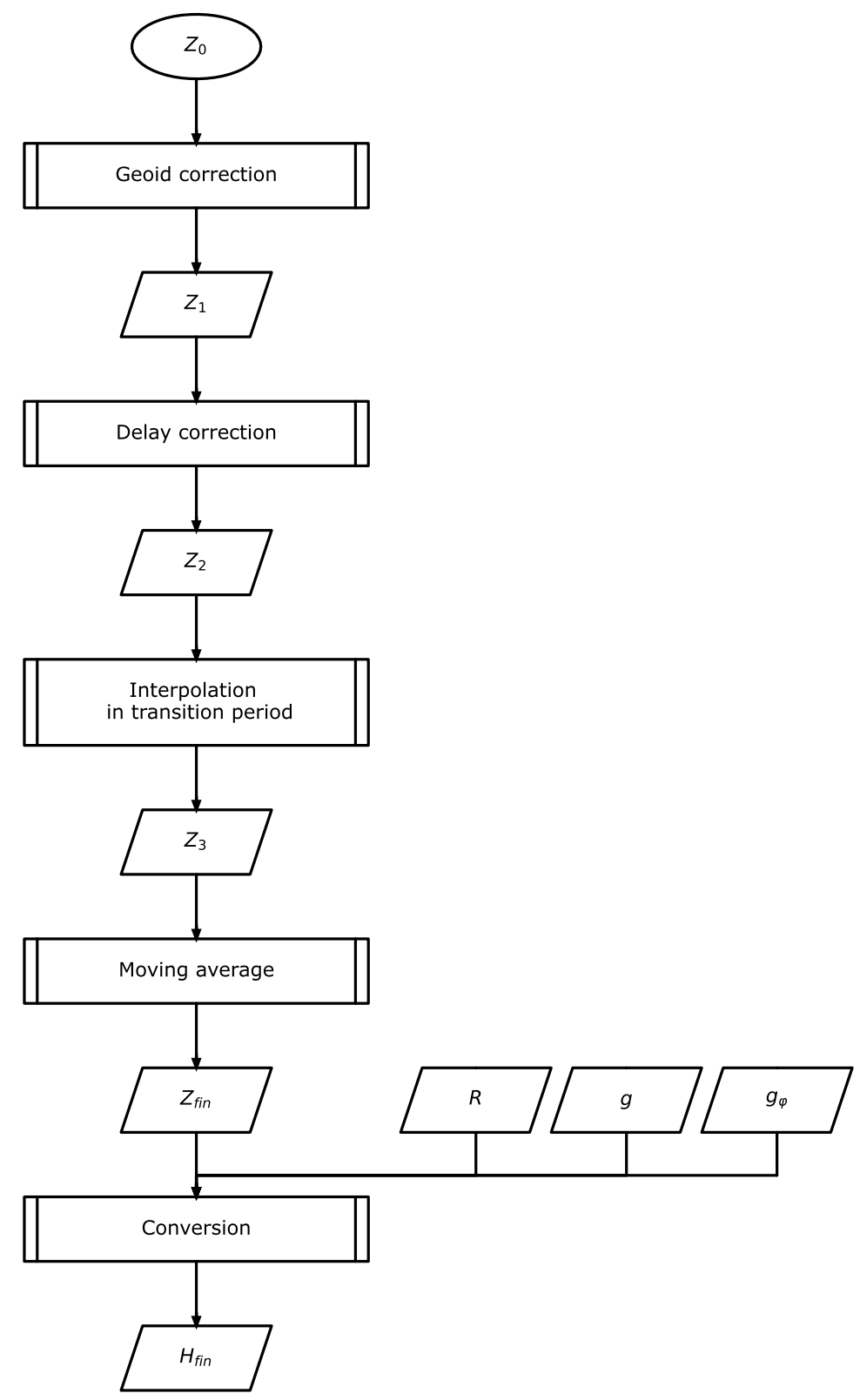

Figure 5. As per Fig.3, but for geometric altitude, $Z$, and geopotential height, $H$ 
https://doi.org/10.5194/amt-2021-374

Preprint. Discussion started: 23 February 2022

(c) Author(s) 2022. CC BY 4.0 License.
Atmospheric Measurement Techniques

Discussions (a) EGM2008

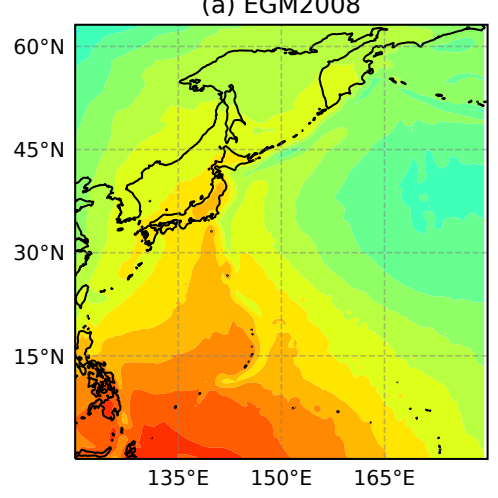

(b) iMS-100

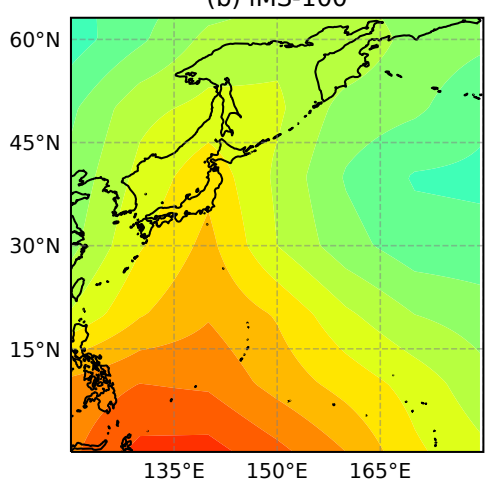

(c) iMS - EGM2008

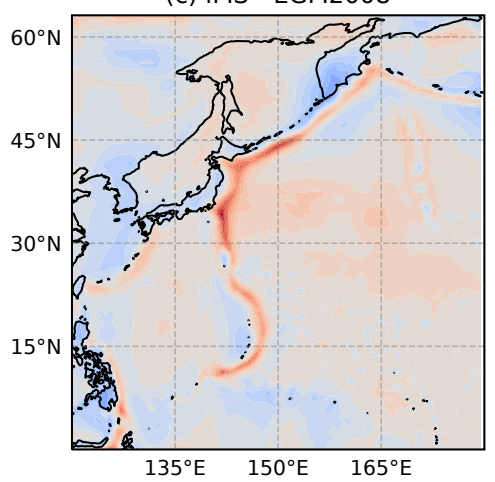

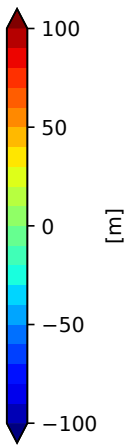

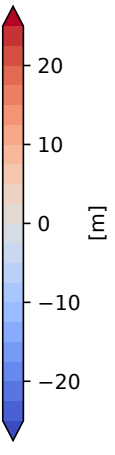

Figure 6. (a) Geoid height for IMS-100-GDP (EGM2008, $\left.5^{\prime} \times 5^{\prime}\right)$, (b) IMS-100 original $\left(10^{\circ} \times 10^{\circ}\right)$, and (c) the difference (Northwest Pacific basin) 
https://doi.org/10.5194/amt-2021-374

Preprint. Discussion started: 23 February 2022

(c) Author(s) 2022. CC BY 4.0 License.
Atmospheric Measurement

Techniques

Discussions

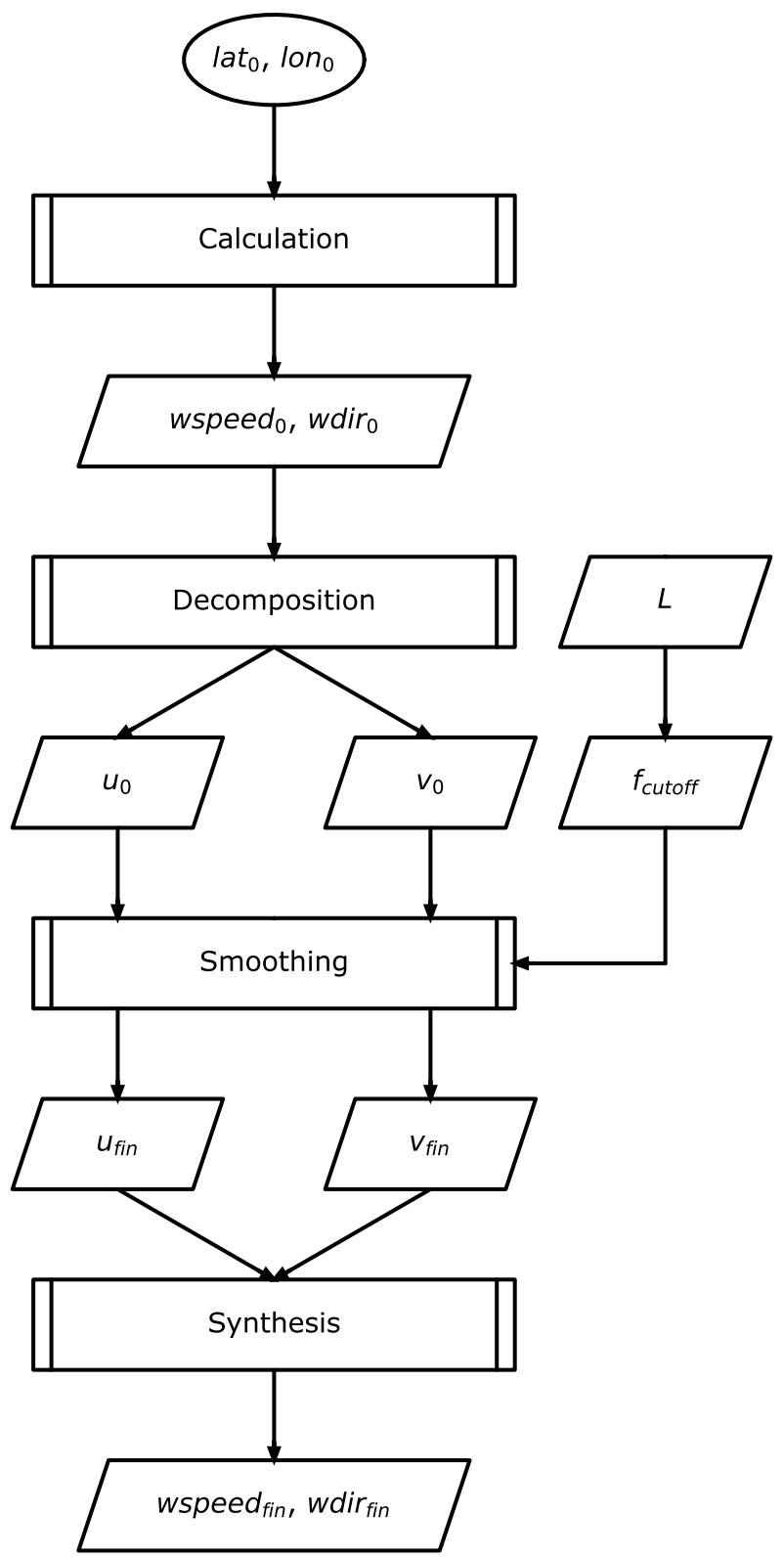

Figure 7. As per Fig.3, but for wind. 
https://doi.org/10.5194/amt-2021-374

Preprint. Discussion started: 23 February 2022

(c) Author(s) 2022. CC BY 4.0 License.

(c) (i)
Atmospheric Measurement Techniques Discussions

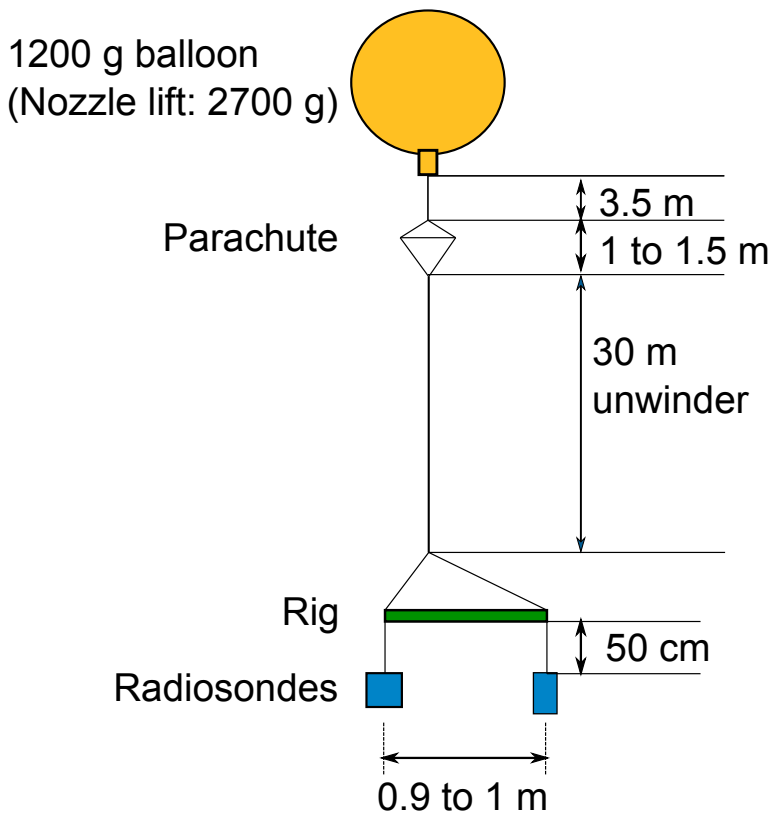

Figure 8. Payload configurations for dual sounding 
https://doi.org/10.5194/amt-2021-374

Preprint. Discussion started: 23 February 2022

(c) Author(s) 2022. CC BY 4.0 License.

(c) (i)

\section{Atmospheric Measurement \\ Techniques \\ Discussions}

Profile at Tateno, 2017-09-22 12UTC
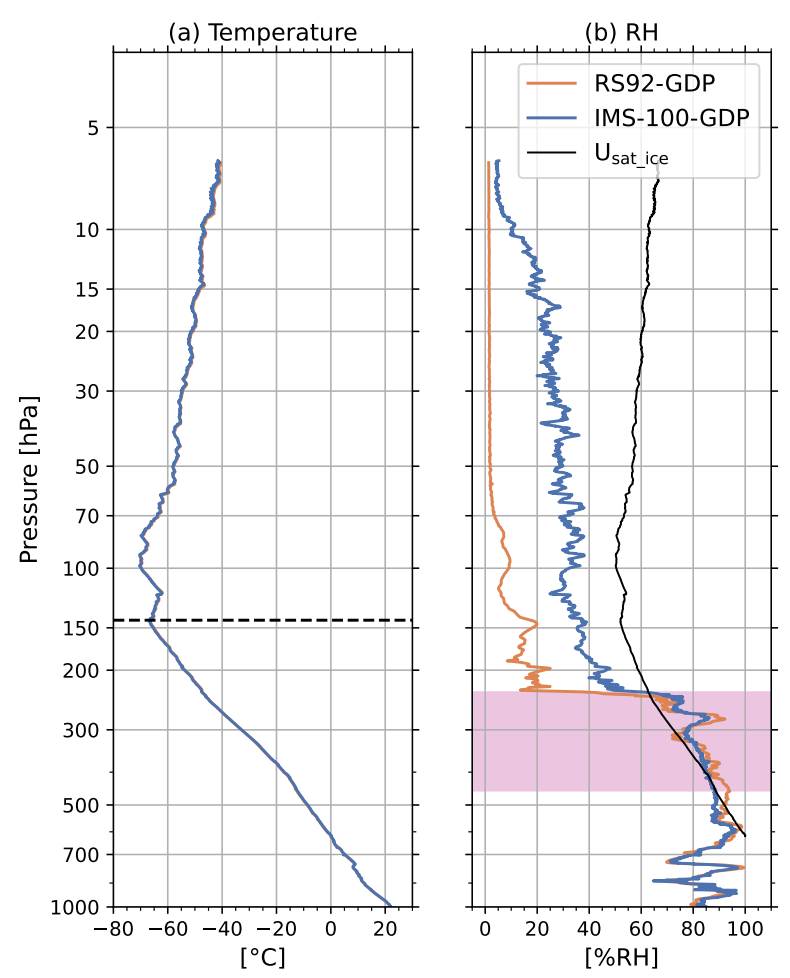

Figure 9. Temperature (a) and RH (b) profiles for RS92-GDP (orange) and IMS-100-GDP (blue) at 12UTC on 22 September 2017. The dashed line in (a) represents tropopause pressure. The black line in (b) shows the RH profile for ice saturated air with IMS-100-GDP temperature; air is supersaturated for ice if the observed RH exceeds this value. Pink shaded layer (453.2 - 232.4 hPa) shows the ISSR for IMS-100-GDP

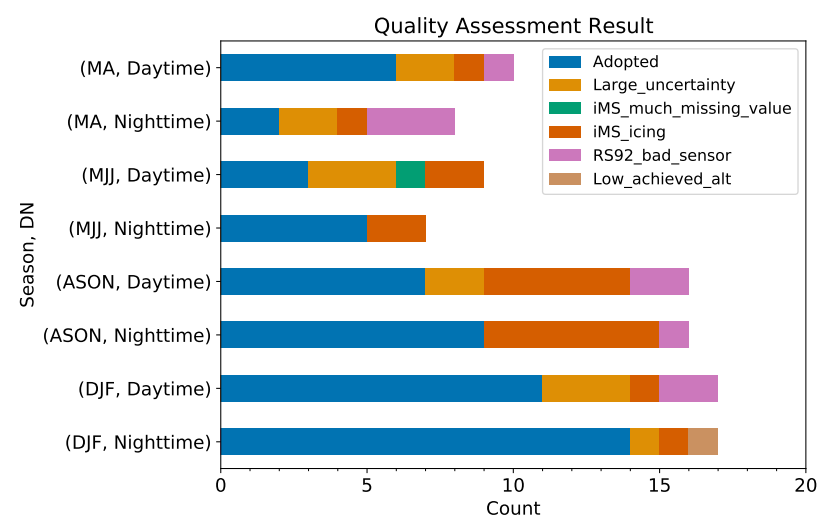

Figure 10. Major factors in data screening. "Adopted" is used for comparison 
https://doi.org/10.5194/amt-2021-374

Preprint. Discussion started: 23 February 2022

(c) Author(s) 2022. CC BY 4.0 License.

(c) (i)

\section{Atmospheric Measurement \\ Techniques \\ Discussions}

Seasonal profile of temperature
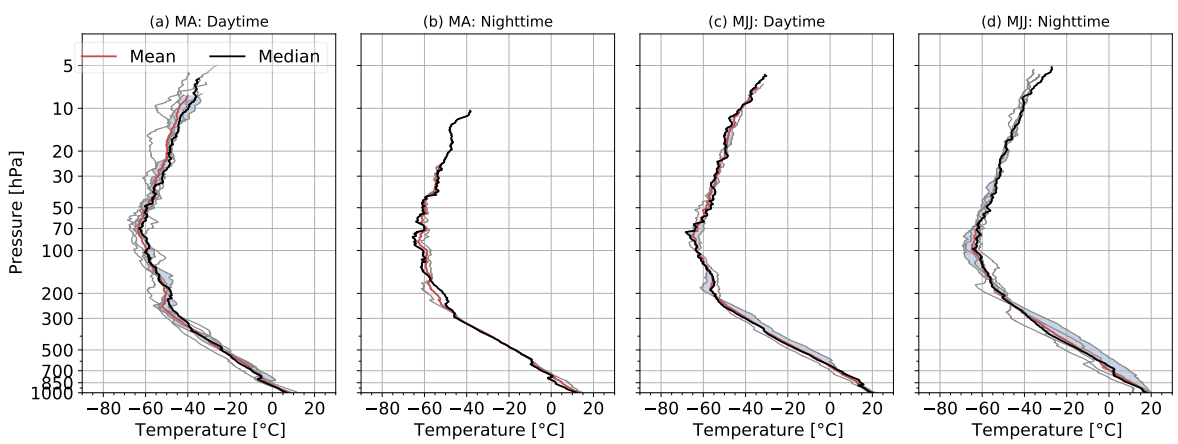

(g) DJF: Daytime

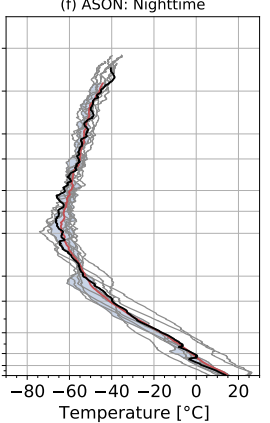

(h) DJF: Nighttime

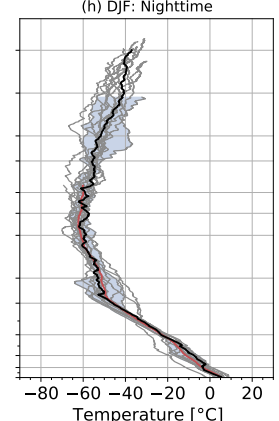

Figure 11. Seasonal profiles of IMS-100-GDP. Gray lines represent profiles for individual flights, red represents profile means, and black represents profile medians. Shading represents $25-75$ percentiles. 

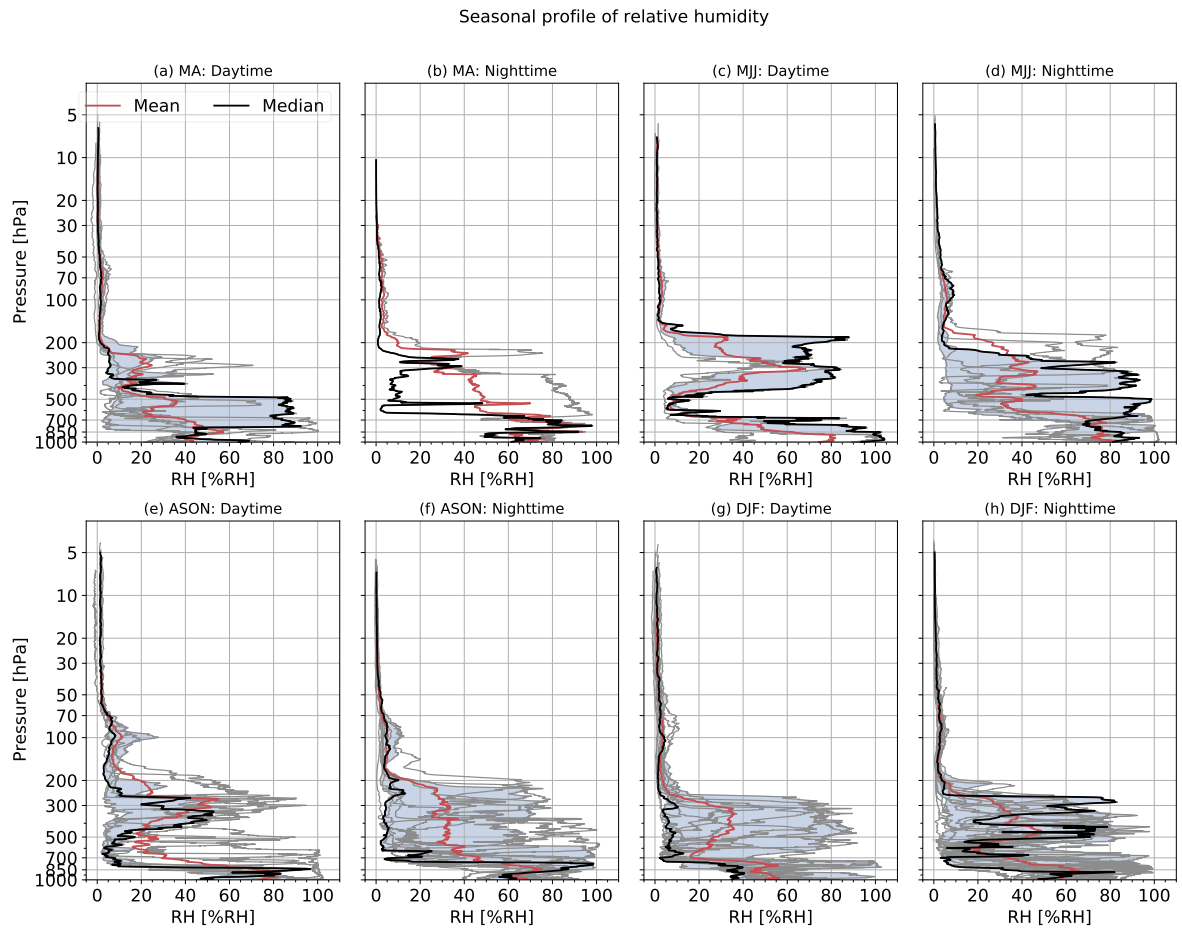

Figure 12. As per Fig. 11, but for RH

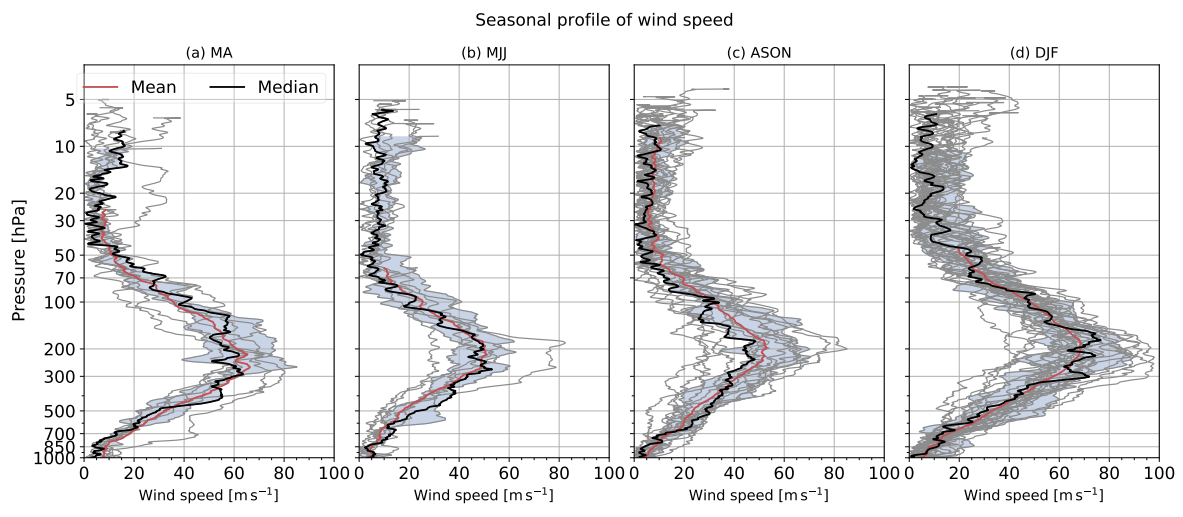

Figure 13. As per Fig. 11, but for wind speed 


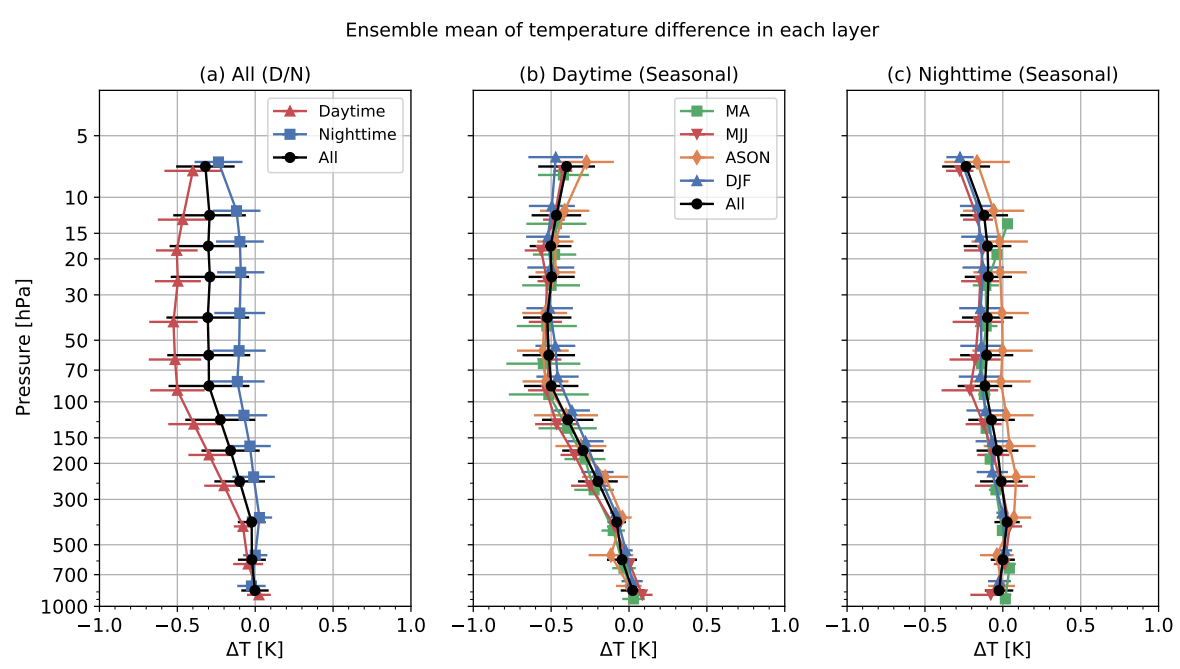

Figure 14. (a) Profiles of ensemble mean temperature differences (iMS-100 minus RS92) with standard deviations (error bars) for all seasons combined. Red, blue and black lines represent daytime, nighttime and all data, respectively. Points are vertically shifted for ease of viewing. (b) As per (a), but representing seasonal profiles for daytime data. The green, red, orange, blue and black lines represent MA, MJJ, ASON, DJF and all seasons, respectively. (c) As per (b), but for nighttime data

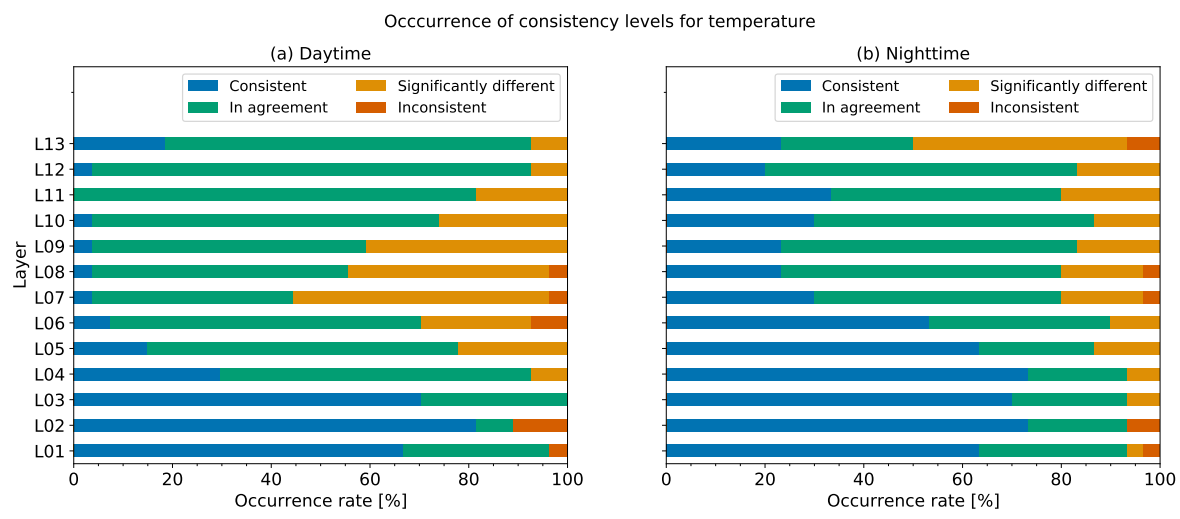

Figure 15. Temperature consistency rank for individual pressure layers 
https://doi.org/10.5194/amt-2021-374

Preprint. Discussion started: 23 February 2022

(c) Author(s) 2022. CC BY 4.0 License.

\section{(c) (1)}

Atmospheric Measurement

Techniques

Discussions (a1)

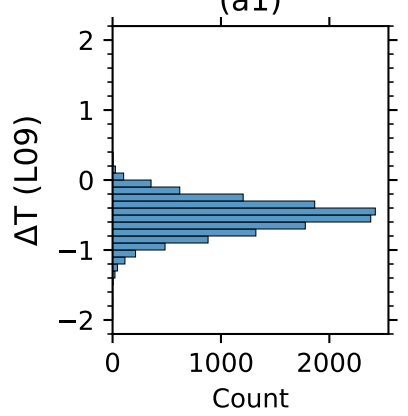

(a2)

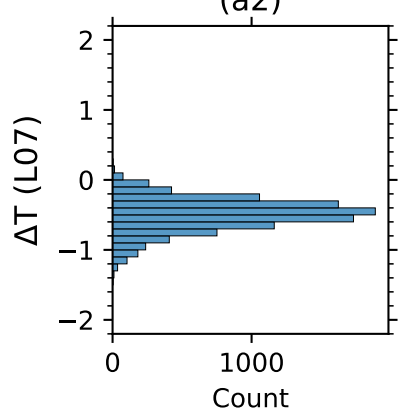

(a3)

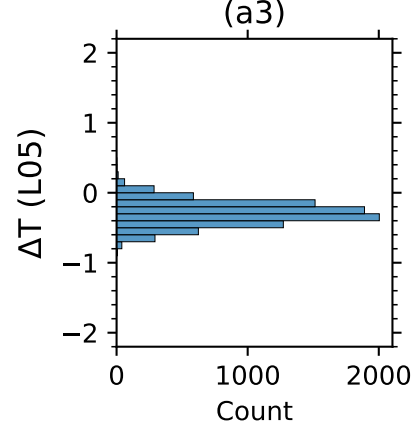

(a4)

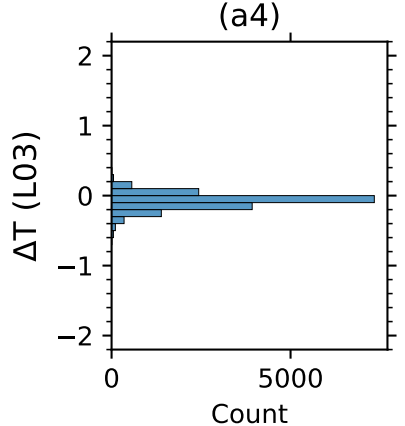

(b1)

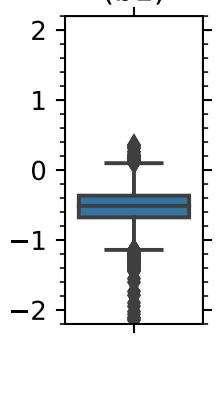

(b2)

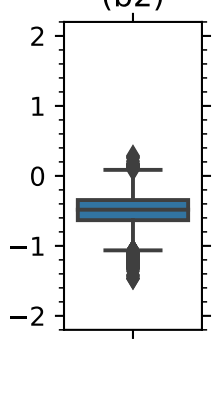

(b3)

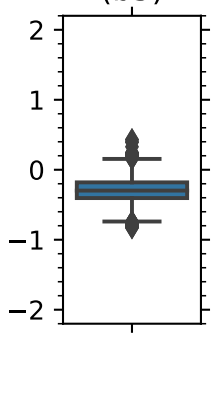

(b4)

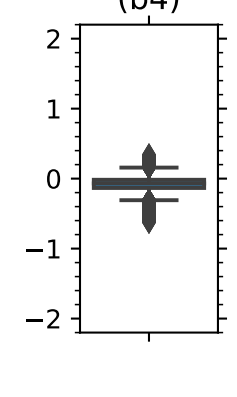

(c1)

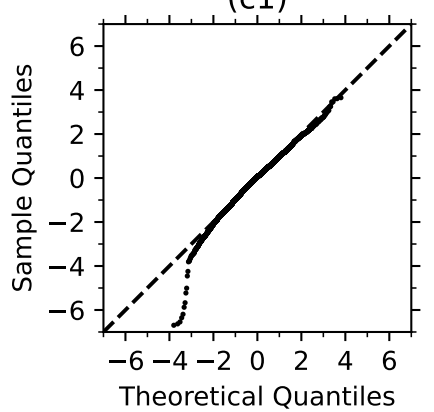

(c2)

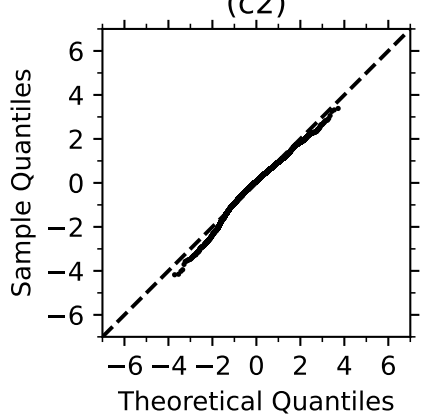

(c3)
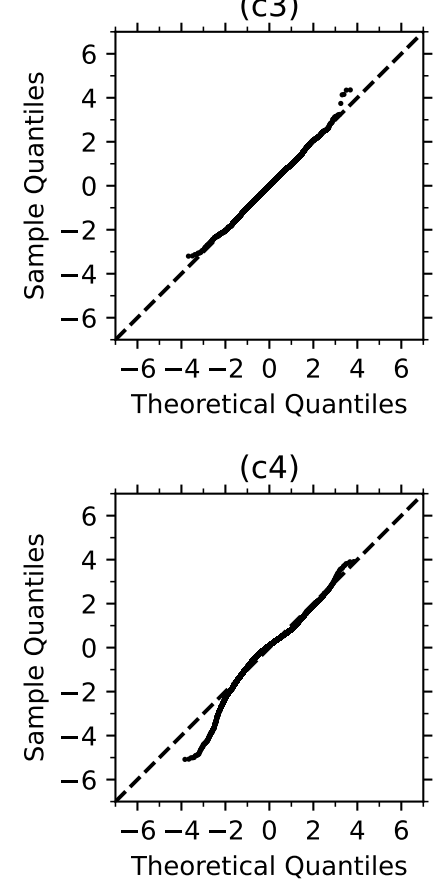

Figure 16. Distribution of temperature differences for daytime observations. aX: histogram; bX: boxplots; and cX: quantile-quantile plots. X indicates layer for (1) L09 (50 - $30 \mathrm{hPa})$, (2) L07 (100 - $70 \mathrm{hPa})$, (3) L05 (200 - $150 \mathrm{hPa}$ ), and (4) L03 (500 - $300 \mathrm{hPa})$ 


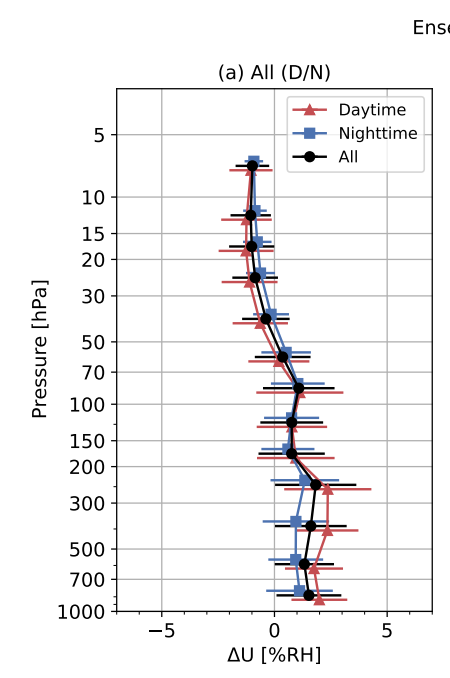

Ensemble mean of RH difference in each layer
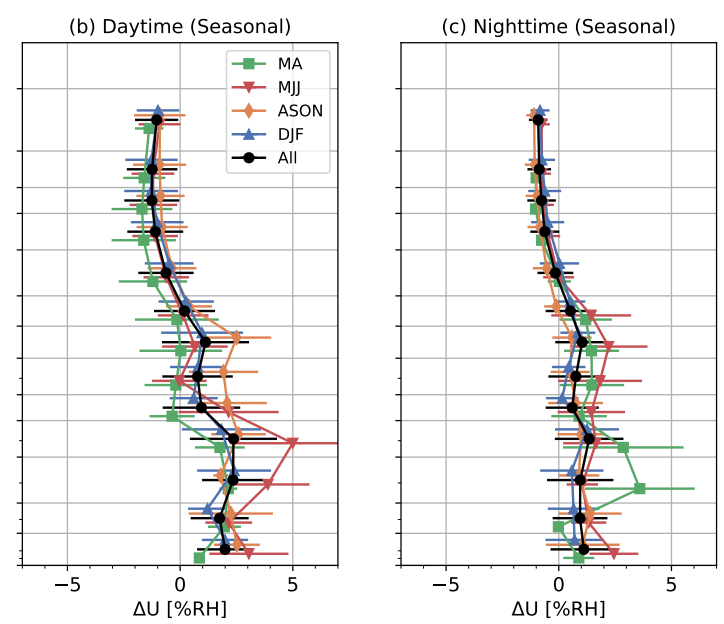

Figure 17. As per Fig. 14, but for RH

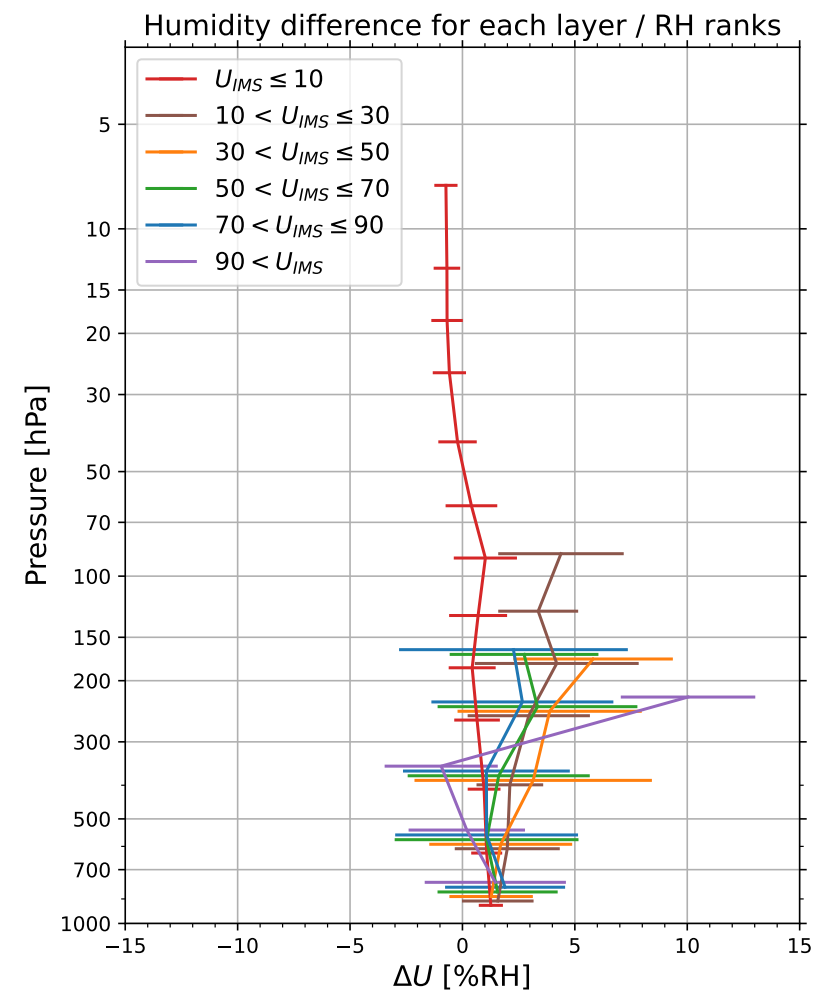

Figure 18. Mean RH difference for six RH ranks 

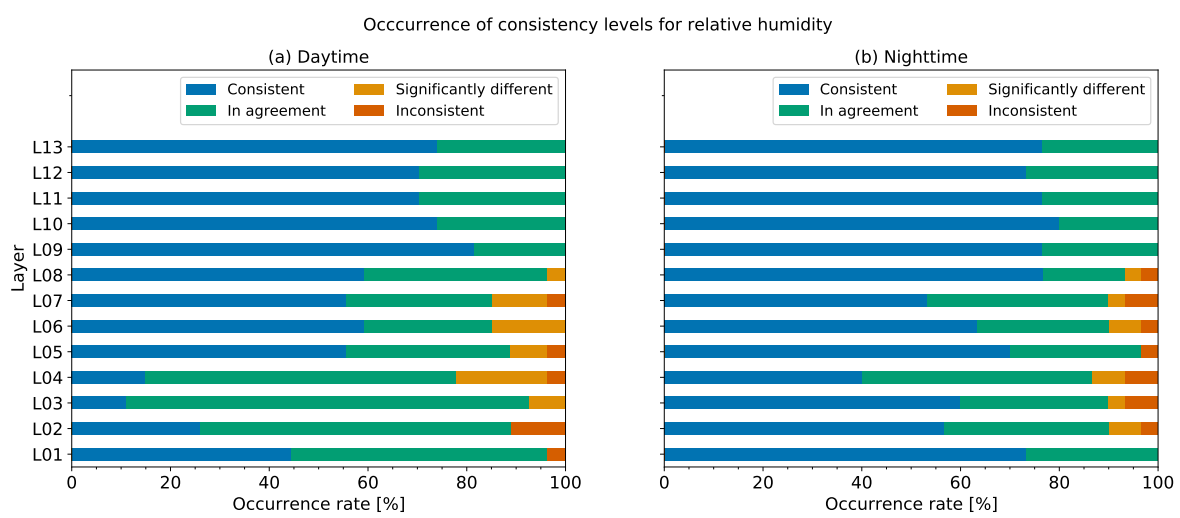

Figure 19. As per Fig.15, but for RH

Profile at Tateno, 2019-04-19 12UTC
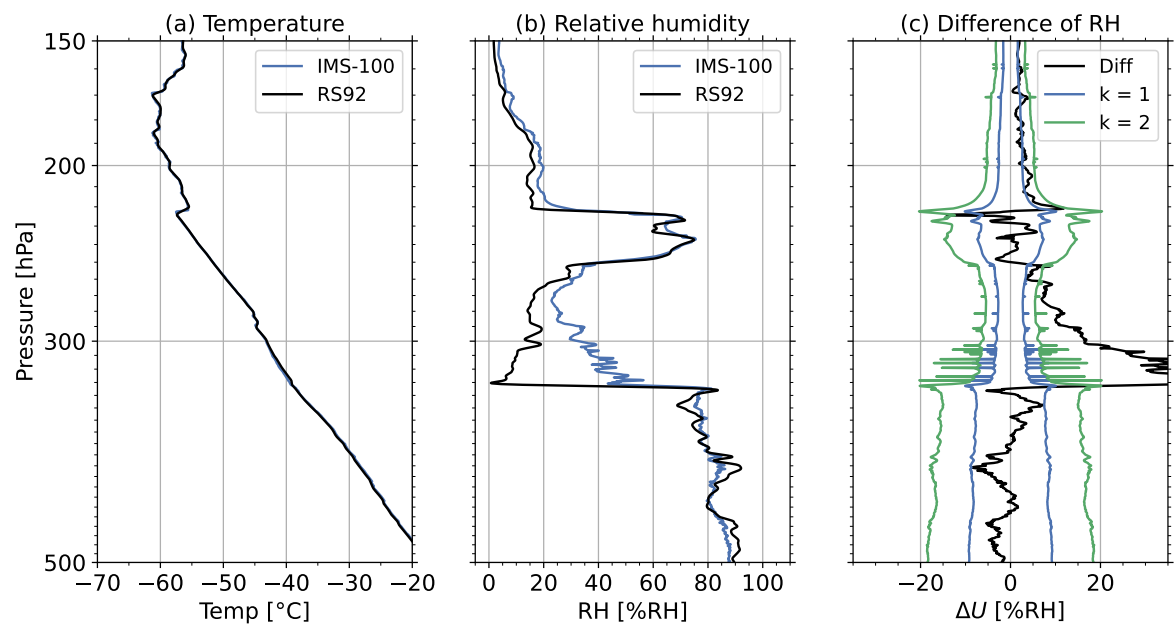

Figure 20. Comparison between 500 and $150 \mathrm{hPa}$ levels (L3 to L5) at $12 \mathrm{UTC}$ (21 LT) on 19 April 2019: (a) temperature, (b) RH, (c) RH difference 


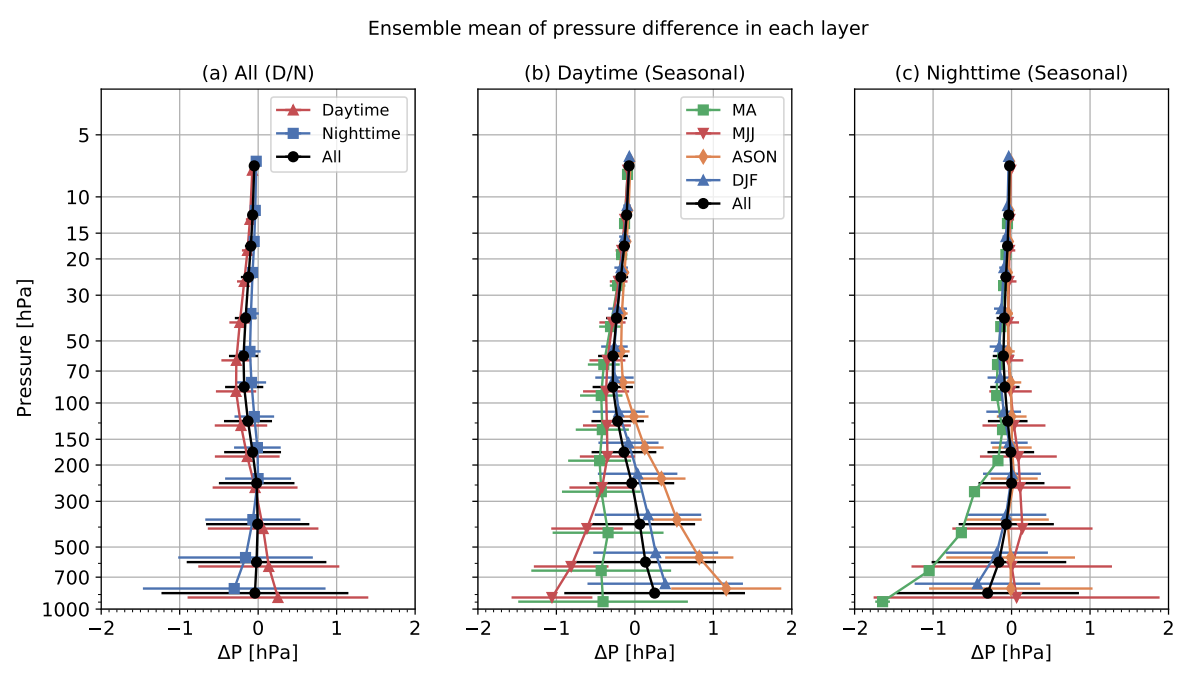

Figure 21. As per Fig. 14, but for pressure

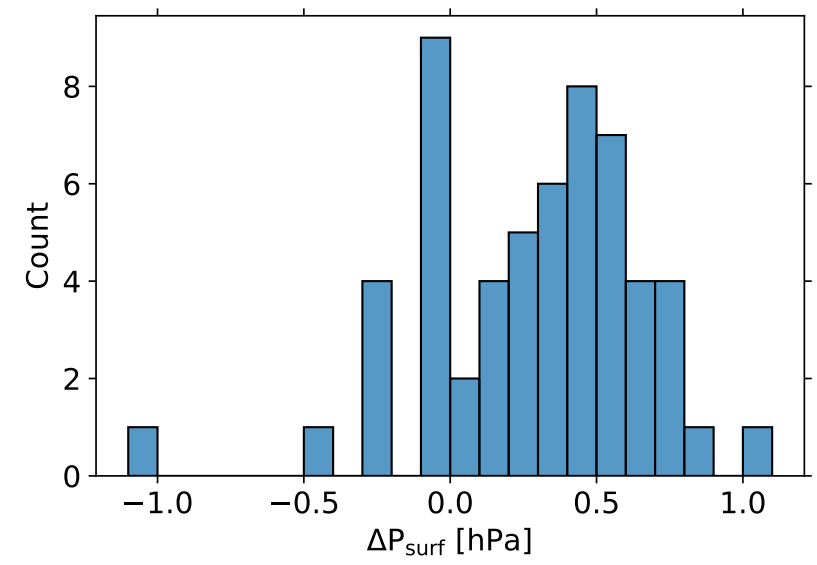

Figure 22. Histogram for the surface pressure difference (RS92 minus barometer values) 

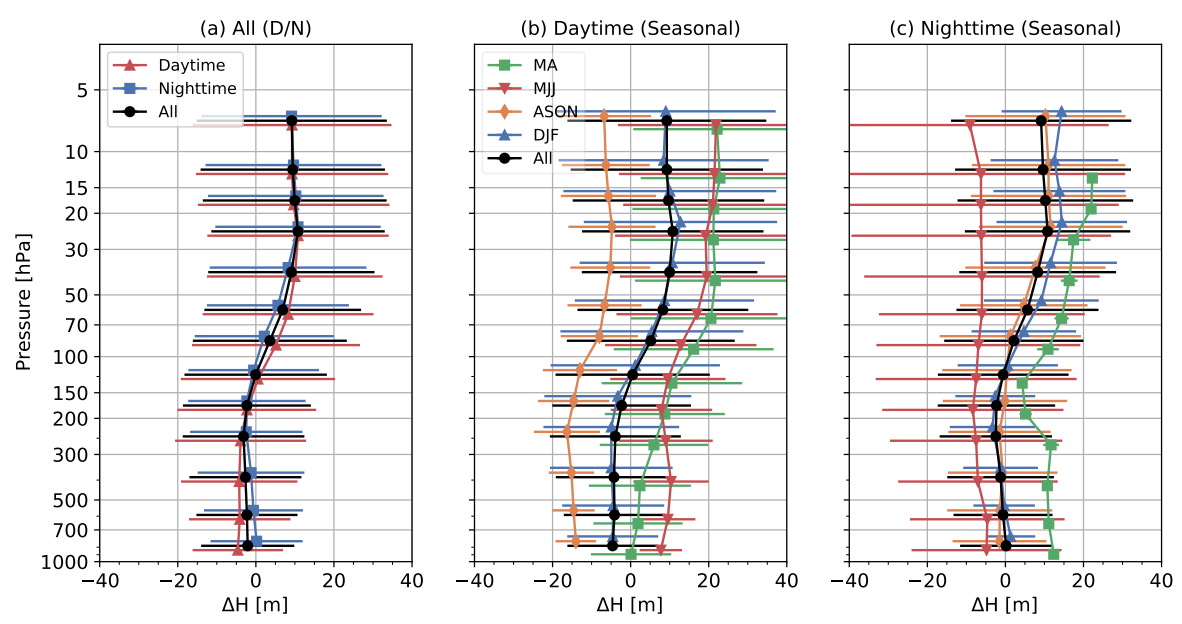

Figure 23. As per Fig. 14, but for geopotential height 
https://doi.org/10.5194/amt-2021-374

Preprint. Discussion started: 23 February 2022

(c) Author(s) 2022. CC BY 4.0 License.

\section{Atmospheric Measurement \\ Techniques \\ Discussions}
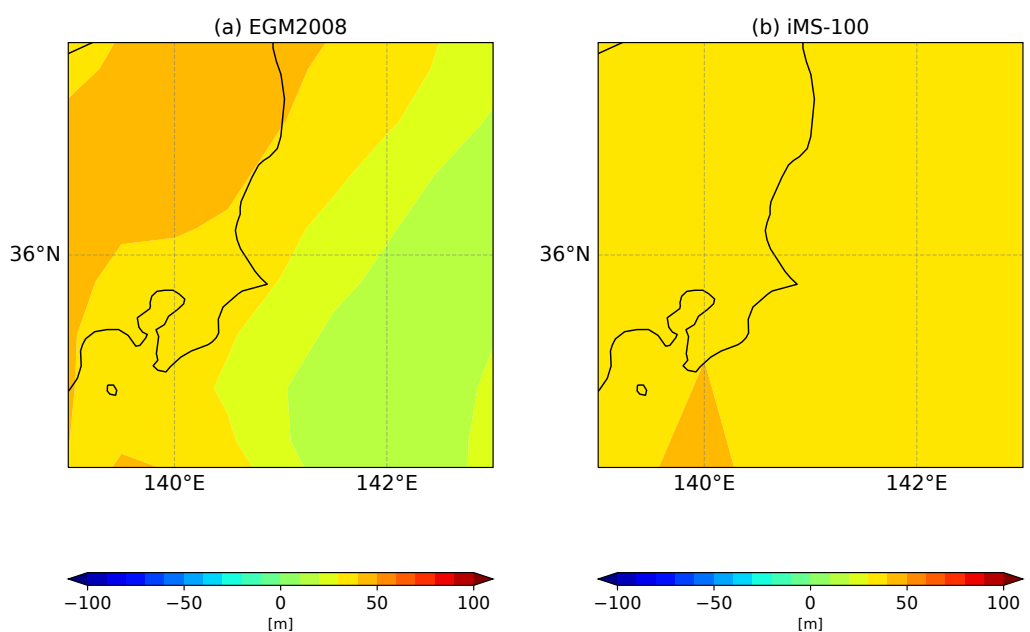

(c) iMS - EGM2008

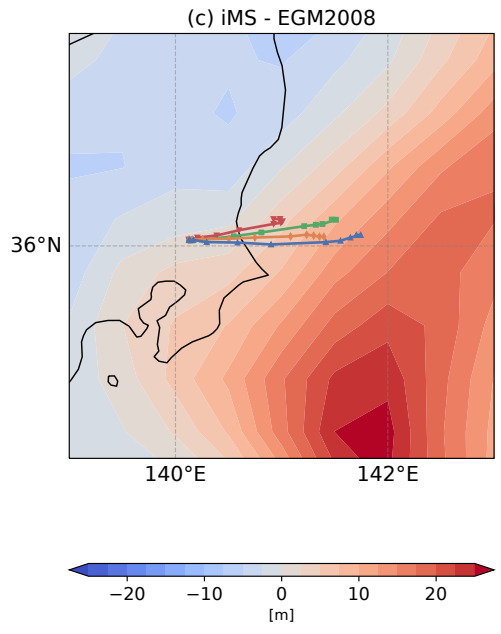

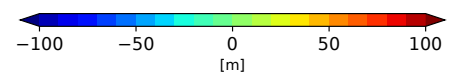

(d) Profile of geoid correction

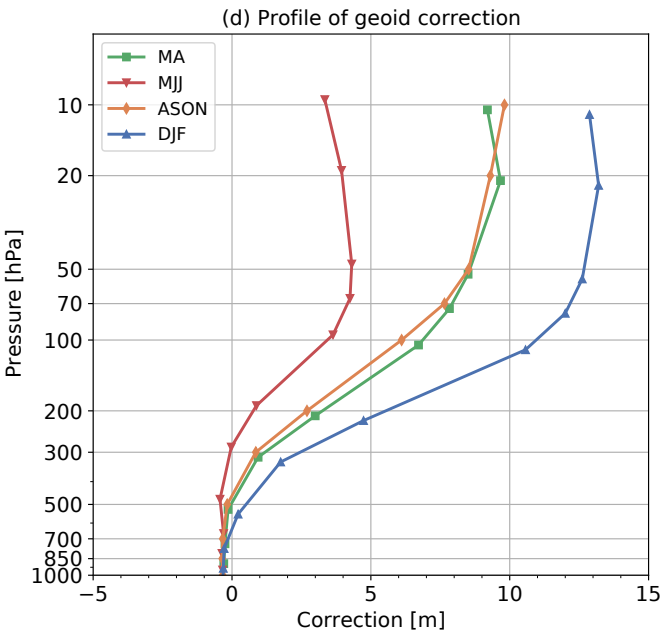

Figure 24. (a) Geoid height for IMS-100-GDP, (b) iMS-100 original, (c) difference of geoid height and seasonal typical tracks, (d) correction values along typical tracks 


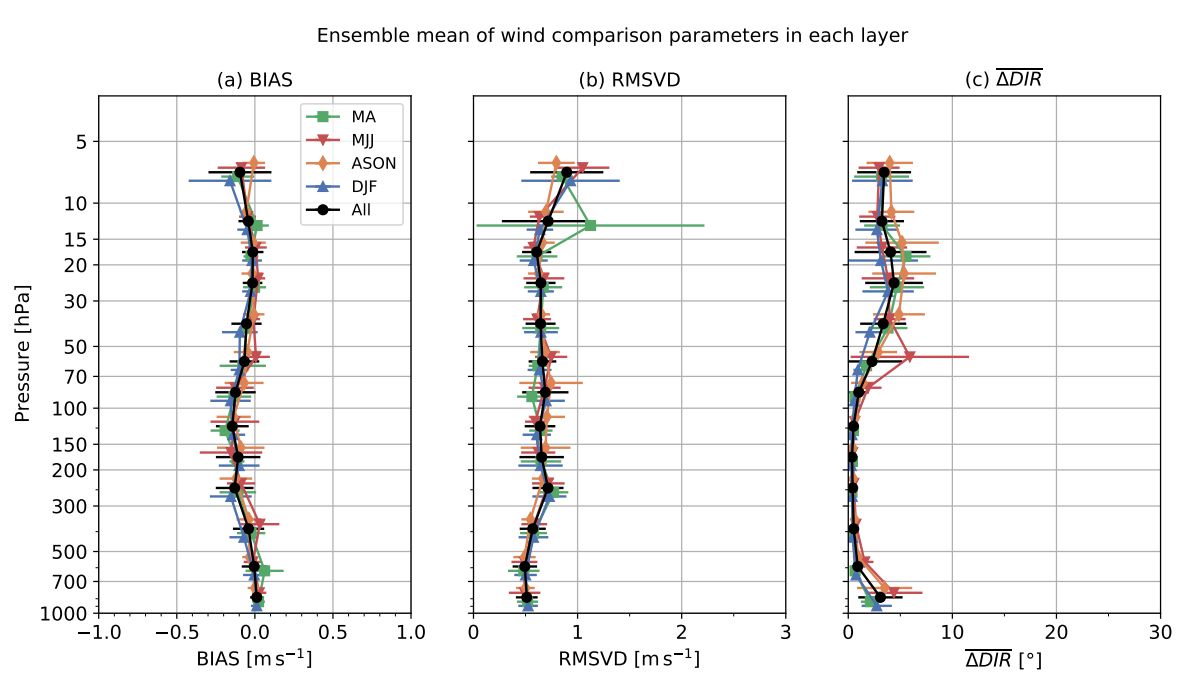

Figure 25. Seasonal wind difference parameters with coloring as per Fig. 14(b): (a) BIAS, (b) RMSVD (c) $\overline{\Delta D I R}$.

Comparison with SKYDEW at Tateno, 2020-10-21 06UTC
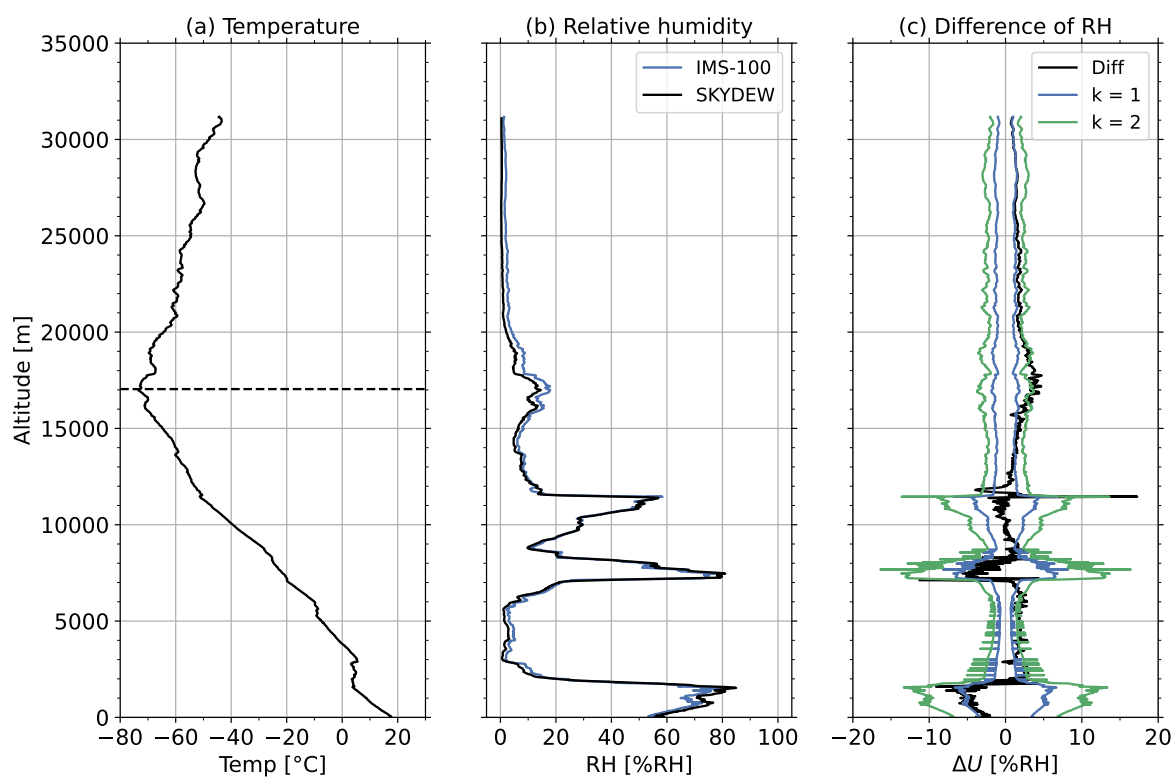

Figure 26. Comparison of RH profiles between IMS-100-GDP and SKYDEW at 06 UTC (15 LT) on 21 October 2020. (a) Air temperature from iMS-100. The dashed line shows the tropopause height (17041.6 m). (b) RH from both. The blue and black lines show IMS-100-GDP and SKYDEW, respectively. SKYDEW RH is calculated from SKYDEW frost/dew-point temperature and iMS-100 air temperature. (c) RH difference in iMS-100 from SKYDEW (black) and RH uncertainty for IMS-100-GDP (blue/green for $k=1$ and 2, respectively). 
Table 1. Specifications of radiosondes (Vaisala Oyj., 2013; Meisei Electric Co., Ltd., 2020; Dirksen et al., 2014; Hoshino et al., 2021)

\begin{tabular}{|c|c|c|}
\hline Radiosonde & iMS-100 & RS92 \\
\hline \multicolumn{3}{|l|}{ Temperature } \\
\hline Sensor type & Thermistor & Capacitive wire \\
\hline Range & $-90{ }^{\circ} \mathrm{C}$ to $+60{ }^{\circ} \mathrm{C}$ & $-90{ }^{\circ} \mathrm{C}$ to $+60{ }^{\circ} \mathrm{C}$ \\
\hline Resolution & $0.1^{\circ} \mathrm{C}$ & $0.1^{\circ} \mathrm{C}$ \\
\hline \multicolumn{3}{|l|}{ Humidity } \\
\hline Sensor type & electrostatic capacitance humidity sensor & thin-film capacitor, headed twin sensor \\
\hline Range & $0 \% \mathrm{RH}$ to $100 \% \mathrm{RH}$ & $0 \% \mathrm{RH}$ to $100 \% \mathrm{RH}$ \\
\hline Resolution & $0.1 \% \mathrm{RH}$ & $1 \% \mathrm{RH}$ \\
\hline $\begin{array}{l}\text { Saturation vapor pressure } \\
\text { formulation }\end{array}$ & Hyland and Wexler equatior & (Hyland and Wexler, 1983) \\
\hline \multicolumn{3}{|l|}{ Pressure / geopotential height } \\
\hline Sensor type & Calculated from GPS altitude & $\begin{array}{l}\text { Silicon pressure sensor and calculated from GPS } \\
\text { altitude }\end{array}$ \\
\hline Pressure range & $1050 \mathrm{hPa}$ to $3 \mathrm{hPa}$ & $1080 \mathrm{hPa}$ to $3 \mathrm{hPa}$ \\
\hline Pressure resolution & $0.1 \mathrm{hPa}$ & $0.1 \mathrm{hPa}$ \\
\hline Calculation & $\begin{array}{l}\text { Pressure is calculated from the GPS geopotential } \\
\text { height using the hypsometric equation }\end{array}$ & $\begin{array}{l}\text { In the lower part of the profile: the pressure sen- } \\
\text { sor is used, and the geopotential height is derived } \\
\text { from pressure using the hypsometric equation } \\
\text { In the upper part of the profile: use the GPS sen- } \\
\text { sor }\end{array}$ \\
\hline \multicolumn{3}{|l|}{ Wind } \\
\hline Sensor / calculation & $\begin{array}{l}\text { Motion vector from GPS positioning (with } \\
\text { SBAS) }\end{array}$ & GPS wind finding (with GBAS) \\
\hline Dimension (DWH) & $53 \mathrm{~mm} \times 55 \mathrm{~mm} \times 131 \mathrm{~mm}$ & $75 \mathrm{~mm} \times 80 \mathrm{~mm} \times 220 \mathrm{~mm}$ \\
\hline Weight (with batteries) & $40 \mathrm{~g}^{[2]}$ & $290 \mathrm{~g}$ \\
\hline \multirow[t]{2}{*}{ Ground system } & MGPS2 (version 3 or higher) & DigiCORA III (version 3.6.4) \\
\hline & & MW41 \\
\hline
\end{tabular}

[1] Wind also can be derived from Doppler shift of GPS signal, like RS-11G. [2] Weight for biodegradable materia model, while $38 \mathrm{~g}$ for EPS model. 
Table 2. Sources contributing to iMS-100 temperature measurement uncertainty.

\begin{tabular}{|c|c|c|}
\hline Source & Value & (Un)correlated \\
\hline Thermistor calibration, $u_{\text {Tcal1 }}$ & $0.3 / \sqrt{3}$ & correlated \\
\hline $\begin{array}{l}\text { Variation in temperature in calibration } \\
\text { chamber, } u_{\text {Tcal2 }}\end{array}$ & $0.13 / \sqrt{3}$ & correlated \\
\hline Spike correction, $u_{\text {spike }}$ & $\sigma\left(\Delta T_{\text {spike }}\right)$ & uncorrelated \\
\hline Moving average, $u_{\mathrm{ma}}$ & & uncorrelated \\
\hline Albedo for radiation correction, & $\left|\Delta T_{\text {albedo }=90 \%}-\Delta T_{\text {albedo }=10 \%}\right| /(2 \sqrt{3})$ & correlated \\
\hline$u_{\text {albedo }(T)}$ & & \\
\hline Ventilation for radiation correction, & $\mid \Delta T(\overline{\operatorname{asc}})-\Delta T\left(\right.$ vent $\left._{\mathrm{pt}}\right) \mid / \sqrt{3}$ & correlated \\
\hline$u_{\operatorname{vent}(T)}$ & $\Delta T\left(\right.$ vent $\left._{\mathrm{pt}}\right)=\sqrt{\mathrm{asc}_{\mathrm{raw}}^{2}+\sigma_{\text {wind }}^{2}}$ & \\
\hline Sensor orientation, $u_{\text {orien }}(T)$ & & uncorrelated \\
\hline Correlated uncertainty, $u_{\text {cor }}(T)$ & $\sqrt{u_{\text {Tcal1 }}^{2}+u_{\text {Tcal2 }}^{2}+u_{\text {albedo }(T)}^{2}+u_{\text {vent }(T)}^{2}}$ & \\
\hline Uncorrelated uncertainty, $u_{\mathrm{ucor}}(T)$ & $\sqrt{u_{\mathrm{spike}}^{2}+u_{\mathrm{ma}}^{2}+u_{\mathrm{orien}}^{2}}$ & \\
\hline Total uncertainty, $u(T)$ & $\sqrt{u_{\mathrm{cor}}^{2}(T)+u_{\mathrm{ucor}}^{2}(T)}$ & \\
\hline
\end{tabular}

Table 3. Sources contributing to iMS-100 relative humidity measurement uncertainty.

\begin{tabular}{|c|c|}
\hline Source & Value \\
\hline $\begin{array}{l}\text { Sensor calibration, } u_{\mathrm{Ucalib}} \\
\text { Time-lag correction, } u_{\mathrm{TL}}(U)\end{array}$ & $\begin{array}{l}2 / \sqrt{3} \\
\frac{\left|U\left(\tau+u_{\tau}\right)-U\left(\tau-u_{\tau}\right)\right|}{2 \sqrt{3}} \\
u_{\tau}=0.25 \tau\end{array}$ \\
\hline \multicolumn{2}{|c|}{$\begin{array}{l}\text { Low-pass filtering in contamination correction, } u_{\mathrm{LPF}} \\
\text { IIR filtering for high-pass component in contamination cor- } \\
\text { rection, } u_{\mathrm{IIR}}\end{array}$} \\
\hline Hysteresis correction, $u_{\text {hys }}(U)$ & $\begin{array}{l}u_{\tau_{-} \text {hys }}=\frac{\left|U\left(\tau_{\text {hys }}+u_{\tau_{\text {hys }}}\right)-U\left(\tau_{\text {hys }}-u_{\tau_{\text {hys }}}\right)\right|}{2 \sqrt{3}} \\
u_{\alpha_{-} \text {hys }}=\frac{\left|U\left(\alpha_{\text {hys }}+u_{\alpha_{\text {hys }}}\right)-U\left(\alpha_{\text {hys }}-u_{\alpha_{\text {hys }}}\right)\right|}{2 \sqrt{3}} \\
u_{\text {hys }}(U)=\sqrt{u_{\tau_{-} \text {hys }}^{2}(U)+u_{\alpha_{-} \text {hys }}^{2}(U)}\end{array}$ \\
\hline TUD correction, $u_{\mathrm{TUD}}(U)$ & Propagated from $u_{\text {hys }}(U)$ \\
\hline Ts/Ta correction, $u_{\mathrm{TsTa}}(U)$ & Propagated from $u_{\mathrm{TUD}}(U)$ \\
\hline Correlated uncertainty, $u_{\text {cor }}(U)$ & $\sqrt{u_{\mathrm{Ucalib}}^{2}+u_{\mathrm{TsTa}}^{2}(U)}$ \\
\hline Total uncertainty, $u(U)$ & $\sqrt{u_{\mathrm{cor}}^{2}(U)+u_{\mathrm{LPF}}^{2}(U)+u_{\mathrm{IIR}}^{2}(U)}$ \\
\hline
\end{tabular}


https://doi.org/10.5194/amt-2021-374

Preprint. Discussion started: 23 February 2022

(c) Author(s) 2022. CC BY 4.0 License.
Atmospheric

Measurement

Techniques

Discussions

Table 4. List of dual sounding events with iMS-100 and RS92 used for comparison. Weather code is according to WMO code table 4677.

\begin{tabular}{|c|c|c|c|c|c|c|c|c|c|c|}
\hline \multirow[t]{2}{*}{$\#$} & \multirow[t]{2}{*}{ Scheduled date } & \multirow[t]{2}{*}{ time (UTC) } & \multirow[t]{2}{*}{ Weather } & \multicolumn{4}{|c|}{ Clouds } & \multicolumn{2}{|c|}{ Achieved level (iMS-100) } & \multirow[t]{2}{*}{ Remarks } \\
\hline & & & & $\mathrm{N}$ & $\mathrm{C}_{\mathrm{L}}$ & $\mathrm{C}_{\mathrm{M}}$ & $\mathrm{C}_{\mathrm{H}}$ & Height $[\mathrm{m}]$ & Pressure $[\mathrm{hPa}]$ & \\
\hline 1 & 15 September 2017 & 00:00 & 02 & 7 & 1 & 3 & 2 & 35406.7 & 5.4 & \\
\hline 2 & 29 September 2017 & 00:00 & 02 & 1 & 1 & 3 & 0 & 35290.6 & 5.5 & \\
\hline 3 & 10 November 2017 & 00:00 & 02 & 4 & 5 & 0 & 0 & 35950.1 & 4.8 & \\
\hline 4 & 17 November 2017 & $12: 00$ & 02 & 7 & 1 & 3 & 2 & 33931.2 & 6.4 & \\
\hline 5 & 1 December 2017 & 12:00 & 02 & 7 & 5 & l & l & 35672.9 & 4.9 & \\
\hline 6 & 8 December 2017 & 00:00 & 03 & 7 & 0 & 3 & 8 & 34446.7 & 5.9 & \\
\hline 7 & 15 December 2017 & 12:00 & 02 & 7 & 5 & l & l & 34188.4 & 6.1 & \\
\hline 8 & 22 December 2017 & 00:00 & 10 & 6 & 5 & 0 & 2 & 33848.8 & 6.6 & \\
\hline 9 & 29 December 2017 & $12: 00$ & 02 & 6 & 0 & 7 & 0 & 34395.5 & 6.1 & \\
\hline 10 & 5 January 2018 & 00:00 & 02 & 7 & 5 & 3 & 2 & 35321.5 & 5.2 & \\
\hline 11 & 19 January 2018 & 00:00 & 10 & 3 & 0 & 3 & 1 & 31732.5 & 8.8 & \\
\hline 12 & 26 January 2018 & $12: 00$ & 02 & 0 & 0 & 0 & 0 & 35054.1 & 5.3 & \\
\hline 13 & 9 February 2018 & $12: 00$ & 03 & 7 & 0 & 3 & 2 & 35864.0 & 4.9 & \\
\hline 14 & 23 February 2018 & $12: 00$ & 11 & 0 & 0 & 0 & 0 & 34358.1 & 5.6 & \\
\hline 15 & 2 March 2018 & 00:00 & 02 & 1 & 0 & 0 & 1 & 33304.7 & 6.6 & \\
\hline 16 & 30 March 2018 & 00:00 & 02 & 1 & 0 & 0 & 2 & 32382.3 & 8.1 & \\
\hline 17 & 13 April 2018 & 00:00 & 02 & 0 & 0 & 0 & 0 & 34787.8 & 5.6 & \\
\hline 18 & 4 May 2018 & $12: 00$ & 02 & 7 & 2 & I & I & 35430.0 & 5.4 & \\
\hline 19 & 25 May 2018 & 00:00 & 02 & 7 & 2 & I & I & 34918.9 & 5.8 & \\
\hline 20 & 1 June 2018 & $12: 00$ & 02 & 7 & 5 & I & I & 36030.3 & 5.1 & \\
\hline 21 & 17 August 2018 & 00:00 & 02 & 4 & 1 & 0 & 1 & 35039.7 & 5.8 & \\
\hline 22 & 28 September 2018 & 00:00 & 28 & 8 & 6 & I & I & 33271.6 & 7.3 & \\
\hline 23 & 19 October 2018 & $12: 00$ & 25 & 7 & 2 & 7 & I & 34918.4 & 5.6 & \\
\hline 24 & 2 November 2018 & $12: 00$ & 02 & 7 & 8 & I & I & 33581.8 & 6.8 & \\
\hline 25 & 9 November 2018 & 00:00 & 21 & 8 & 7 & l & l & 36797.5 & 4.3 & \\
\hline 26 & 16 November 2018 & $12: 00$ & 02 & 7 & 2 & 3 & 2 & 33724.6 & 6.4 & \\
\hline 27 & 30 November 2018 & $12: 00$ & 02 & 7 & 8 & I & l & 33938.2 & 6.2 & \\
\hline 28 & 14 December 2018 & $12: 00$ & 02 & 1 & 5 & 0 & 0 & 33210.2 & 7.0 & \\
\hline 29 & 4 January 2019 & 00:00 & 02 & 0 & 0 & 0 & 0 & 29925.7 & 10.9 & \\
\hline 30 & 11 January 2019 & $12: 00$ & 05 & 0 & 0 & 0 & 0 & 35922.7 & 4.3 & \\
\hline 31 & 18 January 2019 & 00:00 & 02 & 0 & 0 & 0 & 0 & 33459.6 & 6.4 & \\
\hline
\end{tabular}

continued on next page 
https://doi.org/10.5194/amt-2021-374

Preprint. Discussion started: 23 February 2022

(c) Author(s) 2022. CC BY 4.0 License.
Atmospheric

Measurement

Techniques

Discussions

\begin{tabular}{|c|c|c|c|c|c|c|c|c|c|c|}
\hline \multirow{3}{*}{$\#$} & \multirow{3}{*}{ Scheduled date } & \multirow{3}{*}{ Time (UTC) } & \multirow{3}{*}{ Weather } & \multicolumn{7}{|c|}{ continued from previous page } \\
\hline & & & & \multicolumn{4}{|c|}{ Clouds } & \multicolumn{2}{|c|}{ Achieved level (iMS-100) } & \multirow[t]{2}{*}{ Remarks } \\
\hline & & & & $\mathrm{N}$ & $\mathrm{C}_{\mathrm{L}}$ & $\mathrm{C}_{\mathrm{M}}$ & $\mathrm{C}_{\mathrm{H}}$ & Height $[\mathrm{m}]$ & Pressure $[\mathrm{hPa}]$ & \\
\hline 32 & 25 January 2019 & $12: 00$ & 03 & 7 & 0 & 7 & l & 20897.7 & 44.6 & \\
\hline 33 & 1 February 2019 & 00:00 & 02 & 0 & 0 & 0 & 0 & 35588.1 & 5.0 & \\
\hline 34 & 8 February 2019 & $12: 00$ & 02 & 2 & 2 & 0 & 0 & 34432.3 & 6.0 & \\
\hline 35 & 22 February 2019 & $12: 00$ & 61 & 7 & 5 & 7 & l & 34368.1 & 6.0 & \\
\hline 36 & 1 March 2019 & 00:00 & 80 & 8 & 2 & l & l & 32600.4 & 7.9 & \\
\hline 37 & 15 March 2019 & 00:00 & 02 & 1 & 2 & 0 & 0 & 35778.2 & 5.0 & \\
\hline 38 & 22 March 2019 & $12: 00$ & 02 & 7 & 2 & 3 & I & 30755.7 & 10.3 & [1] \\
\hline 39 & 12 April 2019 & 00:00 & 02 & 7 & 5 & 7 & 2 & 34351.5 & 6.2 & \\
\hline 40 & 19 April 2019 & $12: 00$ & 17 & 8 & 9 & I & I & 24879.8 & 25.4 & \\
\hline 41 & 3 May 2019 & $12: 00$ & 02 & 7 & 0 & 3 & 2 & 19487.7 & 60.2 & \\
\hline 42 & 10 May 2019 & 00:00 & 02 & 1 & 0 & 0 & 2 & 33723.9 & 6.8 & \\
\hline 43 & 31 May 2019 & $12: 00$ & 02 & 7 & 0 & 7 & I & 35035.1 & 5.8 & \\
\hline 44 & 21 June 2019 & 00:00 & 10 & 8 & 2 & 7 & I & 33677.6 & 7.1 & \\
\hline 45 & 12 July 2019 & $12: 00$ & 21 & 8 & 0 & 7 & l & 32444.3 & 8.6 & \\
\hline 46 & 23 August 2019 & $12: 00$ & 10 & 7 & 2 & 3 & I & 35233.8 & 5.8 & \\
\hline 47 & 4 October 2019 & $12: 00$ & 02 & 1 & 0 & 3 & 0 & 32421.9 & 8.3 & \\
\hline 48 & 15 November 2019 & $12: 00$ & 02 & 0 & 0 & 0 & 0 & 31786.2 & 8.8 & \\
\hline 49 & 22 November 2019 & 00:00 & 25 & 8 & 8 & l & I & 33575.7 & 6.7 & \\
\hline 50 & 29 November 2019 & $12: 00$ & 02 & 0 & 0 & 0 & 0 & 34727.1 & 5.6 & \\
\hline 51 & 13 December 2019 & $12: 00$ & 02 & 7 & 5 & 0 & 2 & 30668.3 & 10.7 & \\
\hline 52 & 20 December 2019 & 00:00 & 02 & 0 & 0 & 0 & 0 & 33485.9 & 6.6 & \\
\hline 53 & 3 January 2020 & 00:00 & 02 & 0 & 0 & 0 & 0 & 33476.7 & 6.8 & \\
\hline 54 & 10 January 2020 & $12: 00$ & 02 & 4 & 0 & 7 & 2 & 36964.1 & 4.2 & \\
\hline 55 & 17 January 2020 & 00:00 & 02 & 8 & 8 & l & I & 31006.0 & 9.8 & \\
\hline 56 & 24 January 2020 & $12: 00$ & 10 & 1 & 0 & 3 & 2 & 35957.1 & 4.7 & \\
\hline 57 & 31 January 2020 & 00:00 & 02 & 1 & 5 & 0 & 0 & 36588.2 & 4.4 & \\
\hline
\end{tabular}

[1] Truncated due to excessive temperature gaps. RS92 achieved $34434.6 \mathrm{~m}(6.1 \mathrm{hPa})$. 
https://doi.org/10.5194/amt-2021-374

Atmospheric

Preprint. Discussion started: 23 February 2022

(c) Author(s) 2022. CC BY 4.0 License.

Table 5. Pressure range for allocation of iMS-100 - RS92 differences based on RS92 pressure (i.e., bottom $\geq P_{i}^{\mathrm{RS} 92}>$ top)

\begin{tabular}{lrrrrrrrrrrrrr}
\hline Layer \# & 1 & 2 & 3 & 4 & 5 & 6 & 7 & 8 & 9 & 10 & 11 & 12 & 13 \\
\hline Top $[\mathrm{hPa}]$ & 700 & 500 & 300 & 200 & 150 & 100 & 70 & 50 & 30 & 20 & 15 & 10 & 5 \\
Bottom $[\mathrm{hPa}]$ & 1000 & 700 & 500 & 300 & 200 & 150 & 100 & 70 & 50 & 30 & 20 & 15 & 10 \\
\hline
\end{tabular}

